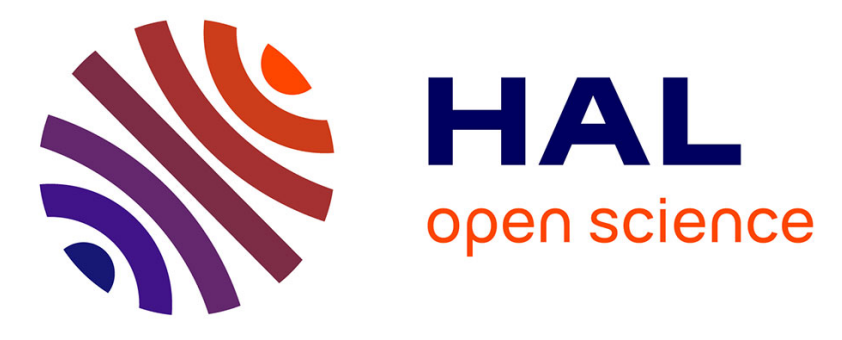

\title{
Amplifying factors leading to the collapse of primary producers during the Chicxulub impact and Deccan Traps eruptions
}

Guillaume Le Hir, Frédéric Fluteau, Baptiste Suchéras-Marx, Yves Godderis

\section{- To cite this version:}

Guillaume Le Hir, Frédéric Fluteau, Baptiste Suchéras-Marx, Yves Godderis. Amplifying factors leading to the collapse of primary producers during the Chicxulub impact and Deccan Traps eruptions. Mass Extinctions, Volcanism, and Impacts: New Developments, 544, , pp.223-245, 2020, $10.1130 / 2020.2544(09)$. hal-03164650

\section{HAL Id: hal-03164650 \\ https://hal.science/hal-03164650}

Submitted on 30 Mar 2021

HAL is a multi-disciplinary open access archive for the deposit and dissemination of scientific research documents, whether they are published or not. The documents may come from teaching and research institutions in France or abroad, or from public or private research centers.
L'archive ouverte pluridisciplinaire HAL, est destinée au dépôt et à la diffusion de documents scientifiques de niveau recherche, publiés ou non, émanant des établissements d'enseignement et de recherche français ou étrangers, des laboratoires publics ou privés.

\section{(ㄷ)(i)}

Distributed under a Creative Commons Attribution| 4.0 International License 


\title{
Amplifying Factors Leading to the Collapse of Primary Producers during the Chicxulub Impact and Deccan Traps
}

\author{
by Le Hir G., Fluteau F., Sucheras B. and Goddéris Y.
}

\begin{abstract}
10 The latest Cretaceous (K; Maastrichtian) through earliest Paleogene (Pg; Danian) interval is a time marked by one of five major mass extinctions in the Earth's history. The synthesis of published data permits the temporal correlation of the K-Pg boundary crisis with two major geological events: 1) the Chicxulub impact discovered in the Yucatán peninsula (Mexico) and 2) the Deccan Traps located on the west-central India plateau. In this paper, environmental and biological consequences

15 from the Chicxulub impact and the Deccan continental flood basalts have been explored using a climate-carbon-biodiversity coupled model called the ECO-GEOCLIM model. The novelty of this study is to investigate how abiotic factors (temperature, $\mathrm{pH}$, and calcite saturation state) act on various marine organisms to determine the primary productivity and biodiversity changes in response to a drastic environmental change. This study shows that the combination of the Deccan

20 volcanism with a $10-\mathrm{km}$ impact led to global warming $\left(3.5^{\circ} \mathrm{C}\right)$ caused by rising carbon dioxide $\left(\mathrm{CO}_{2}\right)$ concentration $(+470 \mathrm{ppmv})$, interrupted by a succession of short-term cooling events, provided by a 'shielding effect' due to the formation of sulphate aerosols. The consequences related to these climate changes are the decrease of the surface ocean $\mathrm{pH}$ by 0.2 (from 8.0 to 7.8 ), while the deep ocean $\mathrm{pH}$ dropped by 0.4 (from 7.8 to 7.4 ). Without requiring any additional perturbations,

25 these environmental disturbances led to a drastic decrease of the biomass of calcifying species and their biodiversity by about $80 \%$, while the biodiversity of noncalcifying species was reduced by about $60 \%$. We also suggest that the short-lived acidification caused by the Chicxulub impact, when combined with the Deccan traps, may explain the severity of the extinction among pelagic calcifying species.
\end{abstract}




\section{Introduction}

The Cretaceous-Paleogene $(\mathrm{K}-\mathrm{Pg})$ boundary is the best-documented mass extinction event, and calcified pelagic plankton provides the most striking example of biotic loss. Among the 131 Late Maastrichtian species of calcareous nannoplankton (i.e., photosynthetic algae producing minute 1$20 \mu \mathrm{m}$ calcite platelets), only 10 to 12 survived into the Danian period (Bown, 2005; Bown et al.,

40 2004), corresponding to a turnover of $\sim 93 \%$ (Bown, 2005). The planktic foraminifera also underwent an important turnover of $70 \%$ to $80 \%$ (Macleod et al., 1997; Molina et al., 1998). The severity of extinction among pelagic calcifying species compared to non-calcareous taxa $(\sim 50 \%$ siliceous diatoms; Macleod et al., 1997) or noncalcifying phytoplankton suggests that a massive acidification of the oceans occurred at the K-Pg boundary (Keller, 2014; Tyrrell et al., 2015).

Prinn and Fegley (1987) were the first to advocate the assumption of a wide dispersal of acid rain $\left(\mathrm{HNO}_{3}\right)$ having a large effect, whereas, using estimates of $\mathrm{SO}_{2}$ released by the $\mathrm{K}-\mathrm{Pg}$ impact, D'Hondt et al. (1994) were the first to propose that sulphur dioxide $\left(\mathrm{SO}_{2}\right)$-induced seawater acidification was an efficient killing mechanism (Sigurdsson et al., 1991, 1992; Pope et al., 1993; Pierazzo et al., 2003). Ohno et al. (2014) simulated an intense and short-lived acidification to

50 reduce the calcite saturation state of the surface ocean, assuming a rapid scavenging of sulphuric acid aerosols (acid rain). A few months later, Tyrrell et al. (2015) contested this finding, demonstrating that a $10-\mathrm{km}$ impactor was too small to repeat the expected decrease in $\mathrm{pH}$.

The bolide scenario was widely accepted in the 1990s when research advances in radiometric dating of large igneous provinces revealed a close temporal relationship between the

55 emplacement of continental flood basalts and oceanic plateaus with the mass extinctions over the last $380 \mathrm{Ma}$ (Courtillot and Renne, 2003). This close temporal match suggests the existence of a cause-and-effect link between the emplacement of the Deccan Traps and the K-Pg mass extinction (Chenet et al., 2009; Courtillot et al., 1986; Courtillot and Renne, 2003; Wignall, 2001), a result challenging the bolide scenario. With an estimated $\sim 2 \times 10^{6} \mathrm{~km}^{3}$ of extruded lava, it has been 
60 proposed that Deccan eruptions have injected massive quantities of gases into the atmosphere over a period not exceeding 700 kyrs (Schoene et al., 2015), spanning the K-Pg boundary.

To assess the consequences of the Deccan Traps on the inorganic carbon cycle, Dessert et al. (2001) used a biogeochemical model and were the first to highlight a significant $\mathrm{pH}$ decrease in seawater $(\Delta \mathrm{pH}=0.3)$ associated with the rise of the partial pressure of carbon dioxide $\left(p \mathrm{CO}_{2}\right.$;

$65 \Delta p \mathrm{CO}_{2}=+1000$ ppmv). The assumptions proposed by Dessert et al. (2001) about the Deccan Traps: 1) the volcanism dynamics (linear and continuous degassing), 2) duration of emplacement (100 or $1000 \mathrm{kyrs})$, and 3) mass of released gases $\left(70,000 \mathrm{GtCO}_{2}\right)$ are become obsolete with research updates. In addition, recent findings have demonstrated the importance of $\mathrm{SO}_{2}$ in the Earth's climate during the Deccan Trap emplacements (Mussard et al., 2014; Schmidt et al., 2016). Considering for 70 the first time the combination of $4090 \mathrm{GtCO}_{2}$ and $3200 \mathrm{GtSO}_{2}$, Henehan et al. (2016) found a decline of surface seawater $\mathrm{pH}$ close 0.2 . They demonstrated that the efficiency of weathering accompanying the induced warming rapidly balances $(50 \mathrm{kyrs})$ the acidification of seawater. Based on this finding, they concluded that the initial environmental perturbation caused by direct gas releases was too weak to explain the major disorders observed in the carbonate record at the K-Pg 75 boundary.

Following the conclusions made by Henehan et al. (2016), this study explores the feedback on inorganic climatic interplays between $\mathrm{SO}_{2}$ and $\mathrm{CO}_{2}$ and organic tolerance of marine primary producers to amplify this initial perturbation. Consequently, a climate-carbon model has been developed, including carbon and sulphur cycles coupled with a biodiversity model describing the 80 behaviour of marine ecosystems. Instead of a standard approach where the primary producers are only represented as a single pool of organic carbon driven by the amount of nutrients available in the ocean (Dessert et al., 2001; Henehan et al., 2016; Petersen et al., 2016; Schmidt et al., 2016; Tobin et al., 2017; Tyrrell et al., 2015), here the biodiversity model splits the oceanic biosphere into $n$ species $(n=50$, see $\mathrm{SI}$ ), each characterised by biological factors (such as death and reproduction 
85 rates) combined with the sensitivity to abiotic factors (seawater temperature, $\mathrm{pH}$, and calcite saturation state).

This paper presents the influence of the Chicxulub asteroid and Deccan Traps at the K-Pg boundary using a carbon-climate-biodiversity model (ECO-GEOCLIM). The key points addressed in this study include the quantification of environmental changes provided by the Chicxulub

90 asteroid and Deccan Traps and their respective effects on the marine biodiversity, highlighting the amplifying response to an initial perturbation caused by inorganic and organic carbon cycles.

The paper is structured as follows. Section 2 describes the modelling approach and the novelty compared to previous modelling studies. Section 3 presents the results of the scenario combining Deccan Traps and/or the bolide impact to identify explanations for the marine fauna

95 turnover at the K-Pg boundary. Subsequently, a comparison is made between the experiment findings and available data and the previous modelling results in Section 4. Finally, the model limitations are discussed in Section 5, before a summary of the key findings is presented in Section 6.

\section{Methods}

\subsection{Model Description}

In this paper, by coupling GEOCLIM and a biodiversity model, a new climate-carbon-biodiversity 105 coupled model (ECO-GEOCLIM) is presented and tested. GEOCLIM (Donnadieu et al., 2006) is a comprehensive climate-carbon model coupling a general circulation model called the fast ocean atmospheric model 1.5 (FOAM 1.5; Jacob, 1997) with a model of the main biogeochemical cycles called COMBINE (Goddéris and Joachimski, 2004). The atmospheric component of FOAM is a parallel version of the National Center for Atmospheric Research's Community Climate Model 2

110 (CCM2) with upgraded radiative and hydrologic physics incorporated in CCM3 v.3.2 (Jacob, 1997).

All simulations have been performed with R15 spectral resolution $\left(4.5^{\circ} \times 7.5^{\circ}\right)$ and 18 vertical levels. In addition, FOAM is used in mixed-layer mode, meaning the atmospheric model is linked 
to a $50 \mathrm{~m}$ mixed-layer ocean with heat transport parameterised through diffusion. The sea ice module uses the thermodynamic component of the CSM1.4 sea ice model, which is based on the

115 Semtner three-layer thermodynamic snow/ice model (Semtner, 1976). No land ice component was included. It is noteworthy that FOAM does not include an interactive chemistry module; all sulphate reactions and climate forcing are computed in COMBINE (for extended details, see Mussard et al., 2014).

COMBINE is a box model that describes the biogeochemical cycles for carbon, phosphorus,

120 alkalinity, oxygen, and sulphates (fig.1 electronic supplementary material). The present version was updated to include the seafloor weathering process as an additional long-term carbon sink (Brady and Gíslason, 1997; Coogan and Dosso, 2015; Krissansen-Totton and Catling, 2017). We divided the oceanic crust into six layers from the seafloor to a depth of $500 \mathrm{~m}$ in the crust, according to a formalism developed by Charnay et al. (2017). Deep water percolating into the oceanic crust

125 follows the present-day temperature gradient (around $116 \mathrm{~K} / \mathrm{km}$ ), starting from the deep ocean temperature at the water-crust interface. To balance the additional carbon consumption from seafloor weathering, the solid Earth degassing rate was increased by $10 \%$ compared to its presentday value (i.e. $6.8 \times 10^{12}$ moles of $\mathrm{CO}_{2} /$ year for aerial volcanoes and $1.8 \times 10^{12}$ moles of $\mathrm{CO}_{2} /$ year for mid-ocean ridges) in agreement with the fluxes presented by Wallmann (2001).

130 For the continental carbon sink, field work shows that silicate weathering is linearly dependent on the mean annual continental runoff, combined with a dependence on the mean annual air temperature through Arrhenius formalism (Walker et al. 1981). Continental weathering fluxes are spatially resolved at the FOAM general circulation model resolution $\left(7.5^{\circ}\right.$ longitude by $4.5^{\circ}$ latitude). The calculated weathering fluxes also depend on continental bedrock lithology (granite vs

135 basalt; Dessert et al., 2001; Oliva et al., 2003). Given the rapid dissolution rate of carbonate rocks, we assume that continental runoff water is at equilibrium with respect to calcite for each continental grid cell under the calculated $\mathrm{CO}_{2}$ level. Sulphur dioxide reactions are computed in the atmospheric box using the parametric laws developed by Pierazzo et al. (2003) and Miles et al. (2004). The 
incoming radiative flux reduction caused by atmospheric aerosols is directly expressed by $\Delta T$,

140 depending on the sulphate aerosols loads $\left(\mathrm{H}_{2} \mathrm{SO}_{4 l i q}\right)$ and sea ice thickness (for details, see Mussard et al., 2014). Recent simulations performed by Schmidt et al. (2016) are used to adjust the climate response of the model (see fig.2 electronic supplementary material).

One-third of the atmospheric aerosols are assumed to fall over continents, and the remainder go directly to the surface ocean. Over continents, sulphuric acid aerosols instantaneously react with

145 the available carbonates and alter the weathering process (Donnadieu et al., 2006; Guidry and Mackenzie, 2000). The riverine input flux of sulphate ions into the oceans is calculated as the product of the runoff and ion concentrations. For oceans, $\mathrm{H}_{2} \mathrm{SO}_{4 \text { liq }}$ primarily acts on the alkalinity budget and associated processes (e.g. the carbonate saturation state). Sulphate anions are also transported into the global ocean by ocean mixing within a few thousand years. In the absence of

150 fully coupled simulations, including active oceanic dynamics, oceanic transport processes occurring in the biogeochemical model are represented by exchange fluxes between the ten-box model. These fluxes have been calibrated on present-day conditions and have held constant in all the simulations, given the lack of information about the changes in ocean mixing in the geological past.

To assess the oceanic environmental disturbance, long-term simulations ( $>100,000 \mathrm{yrs})$ are

155 required. Since the length of simulations of general circulation models cannot exceed a few thousand years, the coupling procedure between FOAM and COMBINE is done through interpolations of the climate runs. Moreover, FOAM is used to generate an off-line catalogue of continental air temperature $\left(T_{\text {air }}\right)$ and continental runoff $(R)$ values for a wide range of $p \mathrm{CO}_{2}$ values. At each time step of the GEOCLIM calculation, and for each corresponding atmospheric $p \mathrm{CO}_{2}, T_{\text {air }}$ 160 and $R$ above each continental pixel are calculated through a linear interpolation procedure from the climatic catalogue.

In the GEOCLIM model, the oceanic biosphere is modelled as an organic carbon reservoir in the photic zone in each oceanic basin. Up to now, these reservoirs are fed by a flux of primary productivity, dependent on the input of phosphorus (the only nutrient modelled) inside the surface 
165 ocean by upwelling or continental discharge. Biomass is then lost by decay and transferred to the deep ocean. In the present study, we introduce a highly simplified model for the biodiversity inside the photic zone. A fixed number of planktonic functional types (PFTs) $n$ is prescribed $(n=50$ in this study). These PFTs are represented by a mass of carbon (mol of C). Each PFT has its own physiological parameters and can interact with the others (primarily competing for resources; Quere et al., 2005). The growth rate of each PFT, $\alpha_{i}$, is a function of the calculated surface temperature and $\mathrm{pH}$ according to the following equation:

$$
\alpha_{i}=b r_{i} \cdot a_{1}^{i} \cdot \exp \left[\frac{-\left(T-b_{1}^{i}\right)^{2}}{2\left(c_{1}^{i}\right)^{2}}\right] \cdot a_{2}^{i} \cdot \exp \left[\frac{-\left(p H-b_{2}^{i}\right)^{2}}{2\left(c_{2}^{i}\right)^{2}}\right] \cdot I_{i} \cdot F_{i n}^{P}
$$

175 where $b r_{i}$ is the birth rate, and $\alpha_{i}$ is the maximal growth rate of species $i$, modulated by two Gaussian functions. The first one is centred on the optimum temperature of growth $b_{l}{ }^{i}$ with a tolerance of $c_{l}{ }^{i}$, and the second is centred on the optimum $\mathrm{pH}$ of growth $b_{2}{ }^{i}$ with a tolerance of $c_{2}{ }^{i}$. Additionally, the GEOCLIM model calculates the surface temperature $T$ and the $\mathrm{pH}$ at each time step for each ocean basin. The optimal temperature of growth for each PFT, $b_{l}{ }^{i}$, is fixed at the averaged value of the surface ocean reservoir for the pre-perturbation, with a random noise of $\pm 5^{\circ} \mathrm{C}$. The same procedure is applied to the optimum $\mathrm{pH}, b_{2}{ }^{i}$, with the random noise fixed at $\pm 0.1 \mathrm{pH}$. The tolerances (standard deviation $c_{1}{ }^{i}$ and $c_{2}{ }^{i}$ ) are randomly set at a value within the interval $\left[-4^{\circ} \mathrm{C}, 4^{\circ} \mathrm{C}\right]$ and $[-0.3,0.3]$ around the optimum temperature and $\mathrm{pH}$.

The factor $I_{i}$ represents the potential competition for resources among the primary 185 producers. For each species $i$, the existence of a competitive relationship with all the other species $j$ is randomly fixed (yes or no). If there is no competition, $I_{i}$ is set to 1 . Otherwise, it is calculated as the average of all competitive factors $I_{i, j}$. These factors are calculated as a Michaelis-Menten function of the ratio of the biomass of PFT $i$ and $j$. The death rate of each species is assumed to be proportional to their global biomass, with the proportionality constant being fixed randomly prior to the simulations. At this stage, we do not account for a trophic chain, including predators, nor the 
dynamics of ecosystems (the processes of evolution). All PFTs are thus primary producers. If the present version of the model does not explicitly simulate the biomass and behaviour of grazers, the effect of grazers is lumped into the death term of each producer, $F^{p}{ }_{i n}$, the nutrients flux (phosphorus).

To consider the role of carbonate ion concentration in calcification by marine organisms we used the $\mathrm{CaCO}_{3}$ saturation state $\left(\Omega_{\mathrm{CaCO} 3}\right)$. This assumption is based on positive correlation between $\Omega_{\mathrm{CaCO}}$ and the calcification rate, This link is defined as follows (Zeebe and Wolf-Gladrow, 2001):

$$
\Omega_{\mathrm{CaCO} 3}=\left[\mathrm{Ca}^{2+}\right]\left[\mathrm{CO}_{3}^{2-}\right] / \mathrm{K}_{\mathrm{sp}} \text { wherein } \mathrm{K}_{\mathrm{sp}}=\left[\mathrm{Ca}^{2+}\right]_{\mathrm{sat}}\left[\mathrm{CO}_{3}{ }^{2-}\right]_{\mathrm{sat}}
$$

$200\left[\mathrm{Ca}^{2+}\right]$ being constant into the ocean over a period not exceeding few millions of years, here $\sim 20 \mathrm{mmol} \cdot \mathrm{kg}^{-1}$ (Stanlet and Hardie, 1999 ), $\Omega_{\mathrm{CaCO} 3}$ is largely determined by $\left[\mathrm{CO}_{3}{ }^{2-}\right]$. therefore the seawater $\mathrm{pH}$. Using this property, if the ocean is still saturated $(\Omega>1)$ the calcification by marine organisms depends on the saturation state for calcite (see next section for details) or becomes null if $(\Omega<1)$. In this latest case the calcifying organisms are supposed extinct (their biomass is fixed to 0 ).

\subsection{Boundary Conditions: The Late Maastrichtian}

To quantify the K-Pg oceanic disturbance, the latest Cretaceous boundary conditions are applied to ECO-GEOCLIM. Climatic outputs are extracted from Maastrichtian simulations performed by

210 Donnadieu et al. (2009). The land-ocean configuration ( $68 \mathrm{Ma})$ is based on paleomagnetic data, hotspot tracks, geological constraints (Besse and Courtillot, 2002; Dercourt et al., 1993), the circular orbit of the Earth around the sun (eccentricity $=0$ ), and the Earth's obliquity at $23.5^{\circ}$ (this setting leads to an equal annual insolation for both hemispheres). In addition, the solar radiation is reduced by $0.6 \%$ (i.e. $1357 \mathrm{~W} / \mathrm{m}^{2}$ ), according to the stellar evolution models (Gough, 1981). The

215 tested atmospheric $\mathrm{CO}_{2}$ values range from 160 to $2000 \mathrm{ppmv}$ to cover all plausible atmospheric $\mathrm{CO}_{2}$ scenarios for the K-Pg boundary (Caldeira and Rampino, 1990; Dessert et al., 2001). The presumed extent and spatial distribution of the Deccan Traps at the K-Pg boundary are based on the work by 
Lefebvre et al. (2013). Plant cover is extracted from Donnadieu et al. (2009), where GEOCLIM was coupled to the dynamic vegetation model (LPJ; Lund-Postdam-Jena; Sitch et al., 2003). This

220 coupling ensures constant coherence between climate and vegetation cover, which influences the silicate weathering but only through the runoff and temperature variables. The model does not account for other effects of vegetation on continental weathering (such as enhanced weathering by organic acids or the below ground $\mathrm{CO}_{2}$ increase). Since FOAM does not consider the atmospheric chemistry of sulphur, land plants are neither affected by acid rains nor short-term cooling.

The Maastrichtian is considered a period of high carbonate production and deposition (Hay, 2004) with extant carbonate platforms and important chalk deposition (Kiessling et al., 2000, 2003). In light of available data on change during the Phanerozoic, the real extent of tropical carbonate indicates that the latest Maastrichtian carbonate platforms $\left(<30^{\circ}\right.$ latitudes $)$ occupy $\sim 16 \times 10^{6} \mathrm{~km}^{2}$ (i.e., the modern areas of shelfal carbonate accumulation are $\sim 0.6 \times 10^{6} \mathrm{~km}^{2}$; Walker et al., 2002).

230 Consequently, we updated the computation of the carbonate accumulation in shallow water (freef flux) as follows:

$$
\text { freef }=a k c r * \text { ocean surface } * \text { reef } S^{*}(\Omega-1)^{1,7}
$$

where akcr represents the most dominant mode of carbonate production for shallow water (low/high value describes a Cretan/Neritan ocean, respectively), with reefS (areal extent of the tropical

235 carbonate over the Phanerozoic period) as the constant $16 \times 10^{6} \mathrm{~km}^{2}$. Thevolume of the coastal ocean is held constant at $4.86 \times 10^{6} \mathrm{~km}^{3}$.

In the neritic environment, carbonate production remains globally dominated by skeletal debris, such as large benthic foraminifera, rudists, bivalves, echinoderms, ectoprota, and algae with a small contribution from peloids and ooids (Kiessling et al., 2003; Steuber, 2002), while the open 240 ocean was dominated by planktic foraminifera and calcareous nannoplankton. The ecological success of planktic calcifiers during the Mesozoic (Martin, 1995) induced a transition from a Neritan ocean, where the $\mathrm{CaCO}_{3}$ production is driven by neritic organisms living on shelves, to a Cretan ocean dominated by biogenic pelagic $\mathrm{CaCO}_{3}$ precipitation (Zeebe and Westbroek, 2003). 
To represent Cretan and Neritan oceans, we changed the percentage of the primary

245 producers able to calcify in the photic zone. In the case of a Neritan ocean, $33 \%$ of the total biomass of the primary producers living on shelves are calcifiers (which corresponds to 17 PFTs as calcifiers and 33 as non-calcifiers; see fig. 3 electronic supplementary material), and $10 \%$ are in the open ocean (calcifying PFTs are reduced to five). Conversely, in the case of the Cretan ocean, we assumed that biological innovations have led to increasing the percentage to $33 \%$ in the open ocean,

250 while the efficiency of calcifier species living on shelves remains unchanged at $33 \%$ (calcifying PFTs $=17$, noncalcifying PFTs $=33$; see fig. 3 electronic supplementary material).

\subsection{The K-Pg Events and Experimental Set-up}

255 Using the Late Maastrichtian boundary conditions, the weathering of silicates and the simultaneous uptake of atmospheric $\mathrm{CO}_{2}$ leads to stabilising the load of atmospheric carbon at $230 \mathrm{ppmv}$. This value is the result of elevated weathering rates due to emplacement of a large igneous province combined with the paleogeographic impact. Compared to usual estimates for the Late Cretaceous, $500 \mathrm{ppm}<p \mathrm{CO}_{2}<1500$ ppm, our pre-crisis load of $\mathrm{CO}_{2}$ appears too low (Royer, 2006). However

260 the last $\mathrm{CO}_{2}$ compilation shows that the atmospheric $\mathrm{CO}_{2}$ at $65 \mathrm{Ma}$ was close to $280 \mathrm{ppm}$, and may even be below that level (Foster et al., 2017)

Moreover, a tropical climate prevails despite this apparently low load of carbon dioxide. Simulated SSTs present an averaged value $\left[50^{\circ} \mathrm{S}-50^{\circ} \mathrm{N}\right]$ of $18.6^{\circ} \mathrm{C}$, accompanied by a wide latitudinal gradient, $<15^{\circ} \mathrm{C}$ at mid-latitudes to $>25^{\circ} \mathrm{C}$ close to the equator. Since this starting state

265 provided us a description of the Late Cretaceous environment not so far for estimates proposed by proxies (Woelders et al. 2017), we preferred to leave the $p \mathrm{CO}_{2}$ pre-crisis value unchanged, rather than tune the carbon cycle parameterisation (enhanced degassing and weaker weathering).

By fixing the latest Maastrichtian areas of shelfal carbonate accumulation at $16 \times 10^{6} \mathrm{~km}^{2}$ (Walker et al., 2002), the alkalinity was depleted compared to present-day conditions; thus, the 270 ocean was less saturated with calcite $\left(\Omega_{\text {calcite }} \sim 2.2\right.$, instead of $4.5<\Omega_{\text {calcite }}<5$ for the modern ocean). 
the lysocline tends to be much shallower than present-day $(2,7$ instead of $4 \mathrm{~km})$ but no region of the surface ocean becomes undersaturated for calcite $\left(\Omega_{\min }\right.$ polar regions $\left.=2\right)$. This pre-crisis steady state implies that the latest Cretaceous ocean should be more sensitive to any process increasing the dissolved inorganic carbon without adding alkalinity.

To better explore the effect of coupling between environmental disturbances and biodiversity, we tested the effects of the Deccan Traps and/or bolide impact. To assess the effects of biological feedback in response to the Deccan Traps or bolide impact (or a combination of the two), we compared simulations where the primary production does not depend on environmental perturbations ('without biological feedback' experiments, Table 1) with simulations where the physiological parameters of species alter their efficiency in producing organic carbon ('with biological feedback' experiments, Table 1). In the absence of biological feedback, the amount of organic carbon produced is solely controlled by the available nutrients. Most of our runs used the Cretan ocean as the standard condition to fit palaeontological records; however, to highlight the role of pelagic calcifiers as primary producers, we also conducted experiments assuming a Neritan ocean. Table 1 summarises all runs performed in this study.

\subsubsection{Eruptive Sequence of the Deccan Traps}

The Deccan Traps outcrop over vast areas of west-central India and are currently formed by a 2903500 m-thick lava pile. The eruptive sequence established in the Western Ghats, the thickest remnant of the main Deccan province, includes 30 major eruptive events and 41 single lava flows corresponding to a volume of $\sim 253,000 \mathrm{~km}^{3}$ (Chenet et al., 2009). After scaling to the total volume of the Deccan Traps $\left(\sim 2 \times 10^{6} \mathrm{~km}^{3}\right.$; Chenet et al., 2009), more than $75 \%$ of the lava volume is not considered, leading to an underestimation of the number of individual lava flows. Assuming a

295 simple geometry for lava flows and accounting for the estimations of $\mathrm{SO}_{2}$ and $\mathrm{CO}_{2}$ concentrations in basalts (Self, 2006), Chenet et al. (2009) proposed that 15,000 to $35,000 \mathrm{Gt}$ of $\mathrm{CO}_{2}$ and 6800 to $17,000 \mathrm{Gt}$ of $\mathrm{SO}_{2}$ were released into the atmosphere, primarily during the emplacement of the main 
province. We assume that sulphur species have reached the stratosphere due to the pulse-like degassing of the Deccan Traps (Kaminski et al., 2011), as suggested by akaganéite minerals (Font et al., 2017).

The emplacement of the Deccan continental flood basalts started with the eruption of the Northern Deccan province (Malwa plateau and Mandla area), a minor event in terms of volume, dated at $67.3 \pm 0.3 \mathrm{Ma}$, lasting about 1.7 Ma (Schöbel et al., 2014). The main province started erupting during the $\mathrm{C} 30 \mathrm{n} / \mathrm{C} 29 \mathrm{r}$ transition, continued during chron $\mathrm{C} 29 \mathrm{r}$, and finally, ended during 305 chron C29n, straddling the K-Pg boundary (Chenet et al., 2007, 2008). The main province clearly represents the largest volcanic event during which at least $80 \%$ of Deccan lavas erupted. Chenet et al. (2009) suggested that the main erupting phase (Phase 2 according to Chenet et al. 2009) would have been as short as 200 kyrs. Recently, using U-Pb ages on zircon from lava flows collected in the Western Ghats (the main province), Schoene et al. (2015) concluded that the duration of 310 emplacement lasted 0.7 Ma. Unfortunately, the absence of U-Pb ages out of the lowest and highest volcanic units did not allow a conclusion regarding the tempo of emplacement, notably the presence of a hiatus within the eruptive sequence. However, according to Schoene et al. 2019, this considered period covers the emplacement Polardpur and Ambenali formations (ie 66.1 to 65.9Ma), two among the most active phases of the Deccan traps. In addition, these two volcanic events encompass the K-

315 Pg boundary (66.04Ma).

By deciding to focus on a shorter period of time of maximum activity ( $200 \mathrm{kyrs})$ instead of studying 700 kyrs of eruption (Schoene et al. 2016, 2019, Sprain et al. 2019), we considered that the most important factor affecting the Earth's environment was the timing of eruption not the total duration of the emplacement of the Deccan traps. Indeed the emplacement of the main province (as 320 all large igneous provinces) consists of individual lava flows and volcanic pulses made of successive flows erupting over a period that is too short to record the magnetic secular variation $(<$ 100 yrs; Chenet et al., 2008, 2009; Courtillot and Fluteau, 2014). This result implies that the volcanic activity is interrupted by periods of quiescence, occasionally evidenced by thick weathered 
levels (red bole). Following this evidence, we developed a sequence based on a pulse like activity

325 instead of considering a linear degassing, a scenario appearing much more realistic to describe the large igneous province volcanism.

Based on constraints on time, volume, and fluxes of volatiles, we developed a stochastic model to obtain a pulse-like degassing scenario of $\mathrm{CO}_{2}$ and $\mathrm{SO}_{2}$. We fixed the total volume of erupted magma at $2 \times 10^{6} \mathrm{~km}^{3}$, the total emission of $\mathrm{CO}_{2}$ at $28,000 \mathrm{Gt}$, and the emission of $\mathrm{SO}_{2}$ at

$3306,800 \mathrm{Gt}$. We assumed that the volume of lava flows and volcanic pulses follow a Gaussian distribution $\left(m=0, \sigma=5000 \mathrm{~km}^{3}\right)$, meaning that only a few lava flows may exceed $10,000 \mathrm{~km}^{3}$. We fixed the duration of a single volcanic activity equal to $10 \mathrm{yrs}$, whatever the volume of erupted magma. The (first) year of eruption was chosen randomly over a 200-kyr period. The pulse-like degassing scenario contained about 500 eruptive events and was used as an input parameter for the

335 biogeochemical model (for details about the eruptive sequence see fig. 4 electronic supplementary material).

\subsubsection{Gases Released and Solid Particles Ejected by the Chicxulub Meteorite}

The Chicxulub crater (170 km in diameter) in the Yucatán peninsula is due to a collision with an asteroid of about $10 \mathrm{~km}$ in diameter. The sea floor at the target site is composed of a $3 \mathrm{~km}$-thick sedimentary sequence of carbonate rocks $(\sim 35 \%$ dolomite and $30 \%$ limestone $)$ and anhydrite $(\sim 30 \%)$ (Ward et al., 1995). To estimate the amount of $\mathrm{CO}_{2}$ released into the atmosphere by

345 vaporisation, we used the approach developed by Charnay et al. (2017). We tested three values of bulk density: 3320,2490 , and $1660 \mathrm{~kg} \cdot \mathrm{m}^{-3}$ to cover the entire range of cases (pure dunite with $0 \%$, $25 \%$, and $50 \%$ porosity, respectively). Assuming a decarbonation pressure fixed at $60 \mathrm{GPa}$ (Martinez et al., 1995) and a mass fraction of $\mathrm{CO}_{2}$ of $1 \%$ in asteroids (Charnay et al., 2017), the mass of $\mathrm{CO}_{2}$ released by the impactor ranged from $1955 \mathrm{GtCO}_{2}$ to $1260 \mathrm{GtCO}_{2}$. In line with these computations, we considered a mean value of $1400 \mathrm{GtCO}_{2}$, a value in the range of Pierazzo's 
estimate (1998) of $\sim 1471 \mathrm{Gt}$. Our computational tests performed with the same assumptions predicted higher loads of $\mathrm{SO}_{2}\left(\sim 180 \mathrm{GtS}\right.$ or $\left.360 \mathrm{GtSO}_{2}\right)$. However, to be consistent with prior studies, while investigating the Chicxulub impact (Brugger et al., 2017), we prefer to use $100 \mathrm{GtS}$ (or $200 \mathrm{GtSO}_{2}$ ) to represent the load of S released by the platform vaporisation. It is notable that additional sources of carbon due to burned biomass and remineralisation of the dying terrestrial vegetation were not considered.

The mass of ejecta produced by the impact, primarily silicates, is calculated using the approach proposed by Collins et al. (2005) and developed by Charnay et al. (2017). Assuming a density of $2490 \mathrm{~kg} \cdot \mathrm{m}^{-3}$ for the impactor, a total mass of ejecta distributed worldwide reaches $4.42 \times 10^{16} \mathrm{~kg}\left(2.95 \times 10^{16} \mathrm{~kg}\right.$ with a density of $1660 \mathrm{~kg} \cdot \mathrm{m}^{-3}$, and $5.86 \times 10^{16} \mathrm{~kg}$ with a density of $3320 \mathrm{~kg} \cdot \mathrm{m}^{-3}$ ). The weathering of ejecta, a net sink of $\mathrm{CO}_{2}$, is calculated following Sleep and Zahnle (2001). In the absence of modules devoted to include following complex processes nitrogen oxide formation due to atmospheric shock waves (Tyrrell et al., 2015), ozone depletion, and bedrock contamination (Ganino and Arndt, 2009), for example, were not considered. . Since the residence time of water in the atmosphere, it would not have exceeded a few months; thus, we do not consider its effect further.

\subsubsection{Time Coincidence Between Deccan Traps and the Chicxulub Meteorite}

370 Recent high-precision ${ }^{40} \mathrm{Ar}-{ }^{39} \mathrm{Ar}$ dating of the K-Pg boundary in Hell Creek (Montana, USA) and of the Chicxulub (Yucatán, Mexico) impact ejecta shows that these two events are time-coincident within $\sim 32,000$ yrs precision at ca. $66.04 \mathrm{Ma}$ (Renne et al., 2013). The discovery of the oldest spherules in the vicinity of the Chicxulub astrobleme in layers is attributed to C29r (between C30n and C29n), suggesting that the impact occurred at least 10 kyrs later than the main phase of the

375 Deccan Traps (Keller, 2014).

Nevertheless, the sudden outburst of Deccan eruptions, accounting for more than $70 \%$ of the main-phase eruption, occurred within $\sim 100,000$ yrs or less of the K-Pg boundary (Renne et al., 
2015), suggesting a longer interval. Without precise time constraints, to enhance asteroid effects on the environment, we assumed that the Chicxulub impact struck the Earth's surface 100 kyrs later

380 than the inception of the Deccan main province volcanism. It is noteworthy that a sensitivity experiment with a different time coincidence (10 kyrs instead of $100 \mathrm{kyrs})$ presents similar effects $\left(\Delta \mathrm{SST} \sim 0.1^{\circ} \mathrm{C}\right.$, see electronic material fig. 5).

\section{Results}

385

\subsection{Chicxulub Impact Modelling}

Over the five years following the impact, the modelled SST drops by $8^{\circ} \mathrm{C}$ in the low latitudes despite the rise in $\mathrm{CO}_{2}\left(\Delta p \mathrm{CO}_{2}=+120\right.$ ppmv, Fig. 1) caused by rock vaporisation (especially 390 carbonates). In response to sulphate aerosols (Robock et al., 2009; Schmidt et al., 2016), the cooling trend continues for at least three decades after the impact. Because the S-aerosol particles are progressively washed out from the atmosphere, the cooling effect is progressively outweighed by the warming provided by the $p \mathrm{CO}_{2}$ due to its longer residence, which causes post-impact warming of $\sim 1.5^{\circ} \mathrm{C}$ after a century (Fig. 1). Due to the ice-albedo feedback, the warming of polar SST is 395 delayed by about 100 yrs and does not exceed $+0.5^{\circ} \mathrm{C}$.

The post-impact $\mathrm{CO}_{2}$ evolution is highly sensitive to biological feedback. Succeeding a brief increase in $\mathrm{CO}_{2}, p \mathrm{CO}_{2}$ decreases within $1 \mathrm{kyr}$ in the absence of feedback (A-Cretan-2), while several $10 \mathrm{kyrs}$ are needed when feedback is considered (A-Cretan-1). As long as S-aerosol amounts remain high, a transient shutdown of the primary production is simulated when biological

400 feedback is considered (Fig. 2a). The primary productivity briefly increases within the first years after the end of cooling, a phenomenon that could be related to the phosphorus accumulation from previous years. This transient peak can be considered a 'swan song'. After the removal of the excess phosphorus, the primary productivity decreases and reaches its lowest value around a decade after the impact (Fig. 2a). Between 50 and 200 years after the impact, the consumption of nutrients is less 
405 efficient due to environmental changes (Figs. 1 and 3), and the phosphorus content increases (Fig. 2b).

Driven by oceanic disturbances, despite the presence of nutrients (Fig. 2b), primary productivity and oceanic biomass both decline (Fig. 4), especially the calcifying primary producers, due to acidification of the surface ocean (Fig. 3). The recovery of the primary productivity happens 410 over a period of a few centuries (Fig. 2) when pre-impact conditions tend to be restored. In response to the low percentage of residual living biomass (Fig. 4) in the aftermath of the impact, the burial of organic carbon is weakened; thus, only weathering processes efficiently reduce $p \mathrm{CO}_{2}$. Consequently, by including biological species' inherent properties, environmental perturbations lead to creating a sluggish organic carbon cycle characterised by a delayed response of reducing $p \mathrm{CO}_{2}$. Focusing on biogeochemical disturbances, the most severe acidification occurs in surface oceans $(\Delta \mathrm{pH}$ equals -0.15$)$, while the deep ocean remains weakly affected $(<0.1 \mathrm{pH}$; Fig. 3a). However, whatever seawater conditions are tested (Cretan or Neritan), the surface ocean remains oversaturated with calcite $\left(\Omega_{\text {calcite }} \sim 1.3\right.$; Fig. $\left.3 \mathrm{c}\right)$. A puzzling behaviour is observed a few decades after the asteroid impact. Despite the ocean acidification, the model predicts an increase in 420 carbonate precipitation (Fig. 3d), while the surface ocean remains depleted of $\mathrm{CO}_{3}^{2-}$ $\left(1.3<\Omega_{\text {calcite }}<\sim 1.5\right.$; Fig. $\left.3 \mathrm{c}\right)$, a result that is contradictory to the theoretical view, assuming a strict

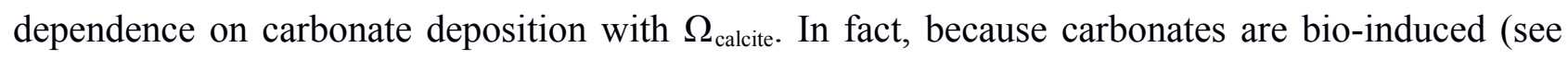
Section 2.2 for details), marine calcifier organisms benefit because all primary producers of abundant nutrients remain available in the surface ocean. Consequently, during the first century

425 after impact, carbonate deposition is dominated by primary productivity rather than by $\Omega_{\text {calcite. With }}$ a longer time scale, $\Omega_{\text {calcite }}$ drives fluctuations of carbonate precipitation. Coastal seas receive the majority of alkalinity fluxes from carbonate and silicate weathering, and carbonate deposits are quickly restored on continental shelves ( $\sim 100$ yrs $)$ compared to open oceans $(\sim 1000$ yrs; Figs. $3 \mathrm{~d}-$ $3 f)$. 
and noncalcifying species, we explored variations of living marine organisms in a Cretan ocean before, during, and after the Chicxulub impact. We developed the following relationships for each PFT in the photic zone, where primary producers are abundant (surface boxes). The present relationship is based on specimen abundance $(S A)$ for each PFT (full details given in footnote ${ }^{1}$ ) and 435 provides an apparent extinction pattern (i.e., apparent species extinction or $a S E$ ).

$$
\begin{gathered}
S A=[\text { PFT biomass }(t=0)-P F T \text { biomass }(t)] / \text { PFT biomass }(t=0) \\
a S E=1, \text { if } S A<S A T, \\
\text { else }=0 M E_{\text {ratio }}=\sum^{l}{ }_{n \text { species }} a S E,
\end{gathered}
$$

440 where $M E$ is the mass extinction ratio and $S A T$ is the specimen abundance threshold.

Based on our assemblage of marine PFTs, A-Cretan-1 case illustrates that, if the overall disturbance is sufficient to trigger a biomass reduction of $60 \%$ for calcifying organisms ( $40 \%$ for noncalcifying; Fig. 4), this results from the collapse of a few dominant calcifying PFTs that were providing the most biomass. Furthermore, biotic losses for primary producers would not have exceeded $20 \%$, assuming an $S A T$ close to 0.1 (i.e., the abundance of living specimens decreases to $10 \%$ of the pre-crisis value). Despite these drastic perturbations, this result suggests that no major extinction occurs when we combine an instantaneous release of $1400 \mathrm{GtCO}_{2}$ with $200 \mathrm{Gt}$ of $\mathrm{SO}_{2}$. Additional sources of carbon due to burned biomass and remineralisation of the dying terrestrial vegetation may enhance this perturbation however but $\mathrm{SO}_{2}$ emissions cannot rise above $250 \mathrm{Gt}-$ threshold of the reversible cooling (see section 4.1 to see sensitivity experiments).

1

We defined the mass extinction ratio based on specimen abundance. We supposed that each type of organism remains characterised by a body shape and mass held constant through time. Biomass $(t=0)$ and $(t)$ correspond to the initial and computed biomass at time $t$, respectively. The specimen abundance threshold (SAT) represents an arbitrary value to describe the apparent presence of specimens in the fossil record. In this study, the arbitrary SAT ranges from 0.2 to 0.01. This range is used to represent the complex set of factors distorting the observed extinction record for each species (the Signor-Lipps effect). According to this assumption, when SAT is fixed to 0.01, the extinction occurs when the apparent abundance of living specimens reduces to $1 \%$ of the pre-crisis value. Based on these equations, species can reappear later in the geological record if the biomass of the species rises. 


\subsection{Deccan Traps Modelling}

To simulate the effects of the Deccan Traps, we computed a sequence of 200 kyrs with pulses following the stochastic distribution as described in Subsection 2.3.1. The response to a single volcanic pulse presents tendencies similar to those simulated for the Chicxulub impact but with a

460 weaker amplitude. Both cases show an abrupt cooling over several decades, driven by S-aerosols, followed by warming caused by enhanced $p \mathrm{CO}_{2}$ after aerosol scavenging. However, through time, the load of $\mathrm{CO}_{2}$ accumulated by degassing by the Deccan Traps overcomes the rise in $\mathrm{CO}_{2}$ triggered by a $10-\mathrm{km}$ impactor, $+250<\Delta p \mathrm{CO}_{2}<+470 \mathrm{ppmv}$ (instead of $+120 \mathrm{ppmv}$ for the Chicxulub impactor; Figs. 5 and fig. 1 in electronic supplementary material).

The primary driver controlling the rise of $p \mathrm{CO}_{2}$ is the degassing itself; however, biological feedback suggests an external mechanism able to amplify the initial perturbation. The mean response obtained with the D-Cretan-1 scenario presents a rise of SST by $3.5^{\circ} \mathrm{C}\left(\sim 23.5^{\circ} \mathrm{C}\right)$ between $50^{\circ} \mathrm{S}$ and $50^{\circ} \mathrm{N}$, whereas the warming does not exceed $2.5^{\circ} \mathrm{C}$ in the absence of biological feedback (D-Cretan-2). This finding demonstrates that the same eruption scenario generated variable

470 environmental disturbances, depending on the properties of the oceanic ecosystem (Fig. 5). Nevertheless, the style of an eruption has a significant influence as well. Examining the linear degassing case (Fig. 5), volcanic sulphur products are washed without disturbing the long-term warming provided by the $\mathrm{CO}_{2}$ (the warming is just slightly weaker due to the continuous S-aerosol formation; D-Cretan-linear) whereas the opposite behaviour is found when the eruptive sequence

475 includes a succession of pulses (the long-term warming is interrupted by a succession of cooling events; D-Cretan-1). The slowing of the weathering process caused by the aerosol-induced cooling is highly dependent on the assumed quiescence period between two pulses. For instance, using a quiescence period twice longer D-Cretan-long-degaz), the excess $\mathrm{CO}_{2}$ is removed from the atmosphere because silicate weathering becomes efficient enough to limit long-term warming (i.e. 
self-regulation of the Earth's temperature; Walker et al., 1981). Consequently, if the eruptive sequence is intense enough, the long-term warming should be briefly interrupted by cooling events lasting 10 to 100 years. Otherwise, the Earth's climate should be characterised by limited long-term warming due to the efficiency of silicate weathering. Despite the importance of emitted $\mathrm{SO}_{2}(\mathrm{D}$ Cretan-noSO $\mathrm{S}_{2}$ ) and aerosol formation in the Earth's climate by limiting silicate weathering

485 (Mussard et al., 2014), the intense build-up of $\mathrm{CO}_{2}$ caused by biological feedback illustrates that organic carbon more efficiently destabilises the global carbon cycle than inorganic processes over the time scale of a thousand years.

Over the first 100,000 years of volcanic activity, what happens at the surface vastly affects the deep ocean, and both parts present the same tendency, although the shift in deep water towards 490 lower $\mathrm{pH}$ is greater than the surface ocean (Fig. 6a). At the opposite end, over the next 100,000 years, the acidification of the surface ocean stops (Fig. 6b), while the $\mathrm{pH}$ of the deep ocean still decreases (Fig. 6a). Acidic seawater affects the deep and surface oceans in varying ways. Most of the calcite is dissolved at depth (Fig. 6c), forcing the lysocline to rise close to $1500 \mathrm{~m}$ (Fig. 6d). The calcite dissolution leads to an increase in deep ocean alkalinity. This increases the propagation to

495 the rest of the ocean due to water upwelling. A positive alkalinity flux is generated from the deep to the surface layers, inhibiting the acidification of surface waters. Consequently, the saturation state of shallow water increases (Fig. 6c), facilitating carbonate production in whatever the initial states of the ocean are considered (Cretan or Neritan).

These experiments reveal contrasting disturbances of the oceans with two distinct phases. 1)

500 Deccan Trap volcanism reduces carbonates deposition and limits the primary productivity in the whole ocean during the first 100,000 years. Then, 2) the deep ocean acidification (lysocline shallowing) enhances the alkalinity flux from the bottom to the surface of the ocean with the direct effect of limiting the surface acidification. This process restores carbonate deposition on shelf surfaces and favours primary production during the second half of the Deccan Trap emplacement $505\left(10^{5}\right.$ to $2.10^{5}$ years $)$. 
The results from oceanic disturbances modelled in D-Cretan-1 run is a biomass reduction of about $90 \%$ for calcifying organisms and $65 \%$ for noncalcifying organisms (Fig. 7). Conversely to the asteroid case (A-Cretan-1), the biomass fall simulated with Deccan Trap volcanism (D-Cretan1) corresponds to a global collapse, whatever the considered PFTs. Calcifying PFTs are more

510 affected because their primary productivity efficiency is affected by the cumulative effect of abiotic factors varying ( $\Delta \mathrm{SST}, \Delta \mathrm{pH}$, and calcite saturation), whereas no calcifiers remain only affected by SST and pH changes. It is noteworthy that most parts of the biomass lost occurred on a time scale ranging from 10,000 to 100,000 years, suggesting that an eruptive sequence that will last longer is not necessarily associated with more drastic environmental changes and biomass crises. If a

515 biomass disturbance seems sufficient to qualify this event as a massive collapse, the patterns of extinction for calcifying and/or noncalcifying PFTs, both ranged from $50 \%$ to $80 \%$, suggest a mass extinction event in terms of marine biodiversity as well.

To specifically investigate the effects of seawater $\mathrm{pH}$ on calcifying and noncalcifying producers, we conducted an additional run in which $\mathrm{pH}$ fluctuations have no effect on the marine 520 biosphere (D-Cretan-3). Compared to standard conditions (D-Cretan-1), after 100,000 years of volcanic activity, the phosphorus content becomes twice lower, while the primary productivity is only reduced by $40 \%$ instead of $60 \%$ (Fig. 8). However, in two cases, we observed a clear inflexion over the next 100,000 years with the re-increase of primary productivity. This tipping point is crossed when the $\Delta \mathrm{pH}$ exceeds 0.1 . Since most of the marine PFTs appear tolerant to $\Delta \mathrm{pH}$ of $\sim 0.1$

525 (Fig. $3 \mathrm{SI}$ ), the organic carbon cycle will not be destabilised below this threshold of fluctuation. As long as changes in seawater $\mathrm{pH}$ do not exceed 0.1 , the primary production remain nearly unaffected, and the productivity curves for both experiments look similar through the first 60-70 kyrs.

After this timespan, we observe that the primary production and phosphorus tendencies appear less pronounced for the D-Cretan-3 experiment (only driven by variations of SST). Finally, 530 in response to a sturdier rate of organic carbon burial linked to a more abundant biomass in oceans, 
the D-Cretan-3 run presents a lower $p \mathrm{CO}_{2}\left(\Delta p \mathrm{CO}_{2}=+420 \mathrm{ppmv}\right)$ compared to standard conditions $\left(\Delta p \mathrm{CO}_{2}=+470 \mathrm{ppmv}\right)$ at the end of the Deccan Traps.

\subsection{The K-Pg Mass Extinction Modelling}

535

We now combine the 200 kyr-long eruptive sequence of the Deccan Traps and the Chicxulub impact, which collided with the Earth 100,000 years after the onset of the degassing of Poladpur (Schone et al. 2019). Compared to the Deccan run (D-Cretan-1 and D-Neritan), the Chicxulub impact leads to an instantaneous, albeit moderate, rise of $p \mathrm{CO}_{2}(+80$ ppmv; Fig. 9a), whatever the

540 state of the ocean tested (Cretan or Neritan). Our model simulates global warming reaching $3.5^{\circ} \mathrm{C}$ due to the rise of atmospheric $\mathrm{CO}_{2}(+470 \mathrm{ppmv})$ only interrupted by intense and brief cooling events due to $\mathrm{S}$-aerosols derived from $\mathrm{SO}_{2}$ emissions by volcanism or rock vaporisation (Chicxulub impact). In addition to SST fluctuations, the spread of sea ice (Fig. 10) should inhibit photosynthesis during most of the year at high latitudes (from the pole to $60^{\circ}$ latitudes). Forced by

545 our volcanic sequence, the Earth has undergone four to five major climate changes (Fig. 10) on a time scale not exceeding 100,000 years (Fig. 9b), with one being caused by the impact and the other driven by intense phases of volcanism.

In addition to climate changes, atmosphere-ocean exchanges lead to a $\mathrm{pH}$ decrease in the global ocean by 0.2 for the surface ocean (from 8.0 to 7.8 ) while the deep ocean $\mathrm{pH}$ drops by 0.4

550 (from 7.8 to 7.4 ). Without requiring any additional perturbations, these environmental disturbances lead to a dramatic decrease in calcifier organisms ( $\sim 90 \%$ of their biomass and $\sim 80 \%$ of their apparent biodiversity, assuming an $S A T$ fixed at 0.1), while noncalcifying organisms appear less affected (biomass and biodiversity are reduced by about $65 \%$ and $60 \%$, respectively). It is noteworthy that mass extinction patterns (Fig. 9e) are affected by the Chicxulub impactor, and the

555 mass extinction ratio of calcifying and noncalcifying species only differs after the impact, suggesting that very rapid marine acidification can be considered an effective trigger for explaining the severity of extinctions among pelagic calcifying species compared to non-calcareous taxa. 


\section{Discussion}

560

Here, we compare our modelling results with prior studies and geological records to validate the mechanisms described in Section 3.

\subsection{Chicxulub Impactor}

565

According to Brugger et al. (2017), the mid-tropical SST underwent a similar cooling $\left(\Delta \mathrm{SST}=-8^{\circ} \mathrm{C}\right.$ in this study compared to $-6^{\circ} \mathrm{C}$ ), whatever the stratospheric residence time assumed for S-aerosols. Both studies used the same amounts of released gases, but the S-aerosol computation is governed by different processes. In ECO-GEOCLIM, the S-aerosol loads are derived from chemical reactions

570 depending the gas amounts with the effect on the climate predicted using a parameterisation based on that by Schmidt et al. (2016). Conversely, CLIMBER3 $\alpha$ follows the assumptions by Pierazzo et al. (2003), but the S-aerosol load is simulated by a reduced solar flux. However, in the absence of direct measurements (high loads of S-aerosols not yet observed), considering the complex interplays of sulphur species in the atmosphere (aerosol size; Timmreck, 2012), the scavenging

575 issue (Ohno et al., 2014), and the altitude of ejection (Kaminski et al., 2011), both estimates of climate change can be considered consistent with the existing data. In addition to these processes, the cooling could be more marked using a mixed-layer oceanic model for computing SST (this study), with the heat transport computation being less accurate than in a fully dynamic ocean model (Brugger et al., 2017).

The reconstructed SST based on $\mathrm{TEX}_{86}$ palaeothermometry for sediments deposited within 100 years following the impact (Vellekoop et al., 2014) also shows a sharp drop in tropical coastal seawater temperature $\left(\Delta \mathrm{SST}_{\max }=-7^{\circ} \mathrm{C}\right)$. The same section (Brazos River, Texas) also reveals a prolonged warming following the 'impact winter', where the post-impact SST is $1^{\circ} \mathrm{C}$ to $2^{\circ} \mathrm{C}$ warmer than the pre-impact values. Compared to our model results for the Chicxulub impact, the 585 best match is observed with the A-Cretan-1 run. Indeed, the data and model results show the same 
sequence of events: intense cooling followed by moderate warming. Without excluding some issues in the recording of such short-lived events (reworked materials), palaeothermometry measurements on the Brazos River section also fit well with the AD-cretan-1 run (Table 1), where distinct cooling phases could be potentially associated with volcanic pulses in addition to the Chicxulub impact.

(Fig. 3) that would be able to create surface waters that are undersaturated with calcite, as defended by Ohno et al. (2014). If the S-aerosol scavenging within a few days may be invoked to solve this issue, this assumption also implies small amounts of stratospheric S-aerosols and a lifespan of Saerosols that is too short to explain the Earth's cooling (Vellekoop et al., 2014).

Following this conclusion, we explored an alternative solution by carrying out a set of experiments where we test the Earth's system response to massive injections of sulphur (D'Hondt et al., 1994; Ohno et al., 2014; Tyrrell et al., 2015). Holding the mass of $\mathrm{CO}_{2}$ released by the impact constant, sensitivity tests revealed that surface waters become very briefly $(<1$ year) undersaturated for calcite $\left(\Omega_{\text {calcite }} \sim 0.95\right)$, with a modest increase of injected sulphur (175 GtS instead of $\left.100 \mathrm{GtS}\right)$. Very massive injections can help to extend the length of the surface ocean undersaturation of calcite, but such high fluxes lead to surface cooling of the Earth. For example, the tropical SST $\left[50^{\circ} \mathrm{S}-50^{\circ} \mathrm{N}\right]$ declines to $0^{\circ} \mathrm{C}$ for 1 year in response to an injection of $250 \mathrm{GtS}$ (surface ocean $\mathrm{pH}=$ 7.6, $\Omega_{\text {calcite }} \sim 0.75$ ) or 10 years with $770 \mathrm{GtS}$ (surface ocean $\mathrm{pH}=7.4, \Omega_{\text {calcite }}<0.5$ ). Beyond this 605 amount of sulphur, an irreversible cooling occurs due to sea ice spreading and snow extending. Within a few years, the Earth becomes entirely covered in ice (snowball Earth state). Although climate instability thresholds due to ice-albedo feedback may be model-dependent, the first-order conclusion rejects the existence of very massive injections of sulphur, a conclusion that is in agreement with findings by Tyrrell et al. (2015). Consequently, based on AD-Cretan runs (Fig. 9), we defend that the likely solution will be a combination of long-term acidification provided by $\mathrm{CO}_{2}$ 
(Deccan Traps) coupled with short-term acidification resulting from the rainout of sulphate aerosols (Chicxulub).

\subsection{Deccan Traps Emplacement}

615

Using $\delta^{18} \mathrm{O}$ measured in foraminifera, the Late Maastrichtian (chron $\mathrm{C} 29 \mathrm{r}$ - planktic foraminiferal zones CF2, then CF1 - last biozones before the K-Pg boundary) was originally identified as a tropical climate ( $\mathrm{Li}$ and Keller, 1998). This view was challenged by recent paleoclimate estimates that suggest a succession of warm-cool events rather than a single global warming event (Punekar et

620 al., 2014). These new data lead to a reassessment of the K-Pg boundary, which may be defined as follows (Keller, 2014): the CF2 zone (spanning 120 kyrs) characterised by an intense warming close to $3^{\circ} \mathrm{C}$ to $4^{\circ} \mathrm{C}$ ( $\mathrm{Li}$ and Keller, 1998), followed by the $\mathrm{CF} 1$ zone ( 160 kyrs), a warm fluctuating period because the warming trend ends in the middle of the CF1 zone, and the Earth's temperature starts to decline. Despite this complexity, all experiments simulating Deccan Traps

625 emplacement (with or without Chicxulub impact) gather all explain some of the major features presented in the geological record: 1) the combination of warm-cool events, 2) warming duration (150-200 kyrs) fitting with foraminifera biozones, and 3) the SST rise in close agreement with proxies $\sim 3.5^{\circ} \mathrm{C}$, which is roughly equivalent to $7^{\circ} \mathrm{C}$ in high latitudes, according to Tobin et al. (2017). The model-proxy agreement emphasises that the emplacement of Deccan Traps seems to be

630 the main driver causing climate changes over the K-Pg boundary.

Tobin et al. (2017) demonstrated the relevance of pulse-like degassing to explain climatic perturbation and revealed a striking correlation between warming and emitted $\mathrm{CO}_{2}$. In their attempt to reproduce $3^{\circ} \mathrm{C}$ to $6^{\circ} \mathrm{C}$ of global warming $\left(7^{\circ} \mathrm{C}\right.$ for polar regions) deduced from oxygen isotopes (Barrera and Savin, 1999; Li and Keller, 1998), Tobin et al. postulated that 35,000 $\mathrm{Gt} \mathrm{CO}_{2}$ must be 635 injected over 200 kyrs for rising $p \mathrm{CO}_{2}$ by $\sim 400$ ppmv and that it warms the Earth's surface by $\sim 3^{\circ} \mathrm{C}$. These estimates were obtained with a box model describing the biogeochemical cycles (GEOCYC, a model derived from GEOCARB) in which the load of atmospheric $\mathrm{CO}_{2}$ is solely driven by the 
enhancement of silicate weathering in response to Earth's heating, with feedback precluding the accumulation of $\mathrm{CO}_{2}$ into the atmosphere. Considering the biological and $\mathrm{SO}_{2}$ feedback, we revised this issue because both mechanisms act as a limiting factor of the carbon consumption. Our model simulates more intense global warming of $3.5^{\circ} \mathrm{C}$ and +470 ppmv for a lower gas release compared to that found by Tobin et al. (2017) $\left(28,000 \mathrm{GtCO}_{2}\right.$ and $\left.6800 \mathrm{GtSO}_{2}\right)$.

\subsection{The K-Pg Calcareous Plankton Diversity Conundrum}

645

The simulated biomass of calcifying and noncalcifying plankton (Fig. 9d) clearly captured the palaeontological pattern of a more important turnover of calcareous plankton (calcareous nannoplankton and planktic foraminifera) in comparison to siliceous and organic plankton (diatoms and dinoflagellates; e.g. Macleod et al., 1997). This difference in plankton type response to the environmental perturbation clearly lies in the carbonate system and $\mathrm{pH}$ degradation, which is more detrimental for calcifying organisms.

Unfortunately, quantitative and semi-quantitative studies on calcareous nannofossil accumulation rates show no decrease before the K-Pg boundary (Bernaola and Monechi, 2007; Henriksson, 1996; Thibault et al., 2016), suggesting that the calcareous nannoplankton productivity

655 (i.e., organic production by calcareous nannoplankton approximated by the accumulation rate of calcareous nannofossil) was not affected by the environmental changes ( $\mathrm{pH}, \Omega_{\text {calcite, }}$ and SST) induced by the onset of Deccan Traps Phase 2. On the other hand, the mass extinction event in relation with the Chicxulub impact clearly decreased the calcareous nannoplankton productivity (Bernaola and Monechi, 2007; Henriksson, 1996; Hull et al., 2011). This singular feature of

660 nannofossils leads the authors to conclude that the Chicxulub impact has a more important influence than the Deccan Traps activity (e.g. Bernaola and Monechi, 2007; Bown, 2005; Gardin, 2002).

This apparent discrepancy between nannoplankton fossils and our model runs may be explainedby Fig.9e. According to these results, the Deccan traps should be responsible of the 
collapse of primary producers while the abrupt short-lived acidification caused by the Chicxulub

665 impact may explain the severity of the extinction among pelagic calcifying species.

\subsection{The K-Pg Mass Extinction}

670 With the K-Pg mass extinction, a collapse of the organic flux from the surface to the deep sea is described due to the decrease in plankton organic production (Strangelove Ocean Hypothesis; Zachos et al., 1989). More recently, a reduction of export of production to the seafloor by a change in organic matter recycling was proposed (Living Ocean Hypothesis; D’Hondt et al., 1998). Nevertheless, these studies were challenged by recent findings. Indeed, the benthic foraminifera did

675 not suffer significantly from the mass extinction event (Alegret et al., 2012; Kaiho, 1992), whereas the organic abundance of algal steranes and bacterial hopanes alongside the recovery of the $\delta^{13} \mathrm{C}_{\text {org }}$ and $\delta^{15} \mathrm{~N}_{\text {org }}$ ratio would suggest a brief (less than a century) reduction in the algal primary productivity (Sepúlveda et al., 2009). A primary productivity proxy, the biogenic barium accumulation rates would suggest a more complex pattern: on one hand, a rapid recovery to no

680 effect in the Central Pacific Ocean or neritic regions of the Atlantic Ocean and, on the other hand, a depressed organic flux in the Southern Ocean, Indian Ocean, and northeast and southwest Atlantic Ocean (Hull et al., 2011).

Our simulations propose some plausible explanations for this regional variability. Indeed, the Deccan Traps induced less important disturbances for calcifying organisms living in the neritic

685 zone than for species living in the open ocean, with the bottom water becoming more aggressive towards carbonate sediments. For the organic matter, the increase in the mean concentration of nutrients in the ocean over the course of the Deccan Traps may enhance the spatial pattern of the primary productivity in the surface ocean. In most regions, dramatic disturbances should lead to a collapse in the organic flux, but restricted areas where upwelling carried an abundant supply of 
nutrients to the surface may remain relatively unaffected, with the load of nutrients overcoming the low efficiency to synthesise organic matter.

Among the biologic oceanic community, the mass extinction event has not affected all the groups the same way (Macleod et al., 1997). The coccolithophores and associated incertae sedis, altogether defined as calcareous nannoplankton, were particularly affected by the mass extinction 695 event with a loss of $93 \%$ of the diversity (Bown, 2005), corresponding to the most important diversity loss of this group since its first occurrence in the Late Triassic (Bown et al., 2004). The pattern of this turnover is particularly interesting. Although the diversity loss seems instantaneous on the geological scale, before the K-Pg boundary, the species richness and relative abundances fluctuate in relation to climatic changes at the end of the Maastrichtian. Most notably, the episode of 700 warming, lasting 200 to $250 \mathrm{kyrs}$ before the K-Pg boundary, has induced an increase in relative abundance of warm-water species, extending the latitudinal range of presence of those species, and was marked by a slight decrease in species richness (Thibault et al., 2016; Thibault and Husson, 2016).

This global warming seems to be associated with the beginning of emplacement of Deccan

705 Traps Phase 2 (Petersen et al., 2016; Thibault and Husson, 2016). Nevertheless, as noted by Thibault et al. (2015), those changes in species richness are relatively weak compared to the diversity and absolute decrease in abundance of calcareous nannofossils in the sediment at the K-Pg boundary (Bernaola and Monechi, 2007; Henriksson, 1996; Hull et al., 2011).

Immediately following the mass extinction, the calcareous nannoplankton community is still

710 dominated by the Cretaceous survivor taxa, which is rapidly replaced by the newly evolving Paleogene species (e.g. Bown, 2005). The switch in the community is associated with a decrease in the size of the coccoliths. The broad pattern is the loss of large Cretaceous species, which are replaced by smaller Paleogene species (Herrmann and Thierstein, 2012). Along with the absolute abundance decrease, this exacerbates the decrease in the carbonate accumulation rate. Nevertheless, 715 in detail, this pattern is challenged by the rapid occurrence in the Paleogene of large coccolith 
(Bernaola and Monechi, 2007; Bown, 2005).The Cretaceous survivors are supposed to be rstrategist species (opportunistic), which are more frequently in high latitudes and neritic environments (Bown, 2005). Those species were more likely to survive a mass extinction event because of their capacity to live in unstable environments with changes in temperature, nutrient concentration, or even $\Omega_{\text {calcite }}$ on a short time scale (days, seasons, or years).

Looking at all of these studies, if some aspects of our results are in accordance with the observed palaeontological pattern, our initial assumptions appear still too simple to capture the complexity of the patterns of K-Pg extinction. Consequently, we highlight in the following section the limitations of this study to present the future improvements.

\section{Limitations}

Our simulations provide an overview of possible patterns of marine primary productivity and biodiversity collapse in response to climate changes and oceanic acidification during a short

730 window (200 kyrs) of the K-Pg transition ( $\sim 1 \mathrm{M}$ yrs). Our simulations suggest that emissions of $\mathrm{SO}_{2}$ and $\mathrm{CO}_{2}$ are first-order triggers of the K-Pg environmental crisis. Considering that short-term processes reveal that the initial perturbation (gas loads of $\mathrm{CO}_{2}$ and $\mathrm{SO}_{2}$ ) may be amplified by two major factors: 1) the type of eruption over the course of 200 kyrs and 2) the inherent biological parameters of marine organisms. Unfortunately, the time computation has led us to limit the number

735 of factors tested. To advise the reader about implications of these choices, the cautions are briefly presented with respect to the limitations of this study.

To assess the potential effect of the Deccan Traps, we conservatively assume that $3.4 \mathrm{Tg}$ of $\mathrm{SO}_{2}$ and $14 \mathrm{Tg}$ of $\mathrm{CO}_{2}$ were degassed for every cubic kilometre of erupted lava. These values are held constant over 200 kyrs. With this approach, we omitted $1 \mathrm{Tg}$ of chlorine per cubic kilometre

740 yield by the Traps (Self et al., 2008). In addition, eruption parameters, such as the effusion rate and tempo, have been considered important to explain environmental effects (Rader et al., 2017). Unfortunately, the lack of information about these parameters has led us to build the eruptive 
sequence using a stochastic approach. Despite the development of a pulse-like emission, the absence of a realistic degassing scenario at the K-Pg boundary implies that major environmental 745 features occurring before or after the Deccan Traps cannot be captured (i.e., pre-event warming accompanied by the rise of M. Murus; Thibault et al., 2017, the post-Traps overshoot or the absence of a progressive warming 100 kyrs before the K-Pg boundary).

In addition, we addressed sensitivity to climate change by computing inherent parameters with random functions (temperature and $\mathrm{pH}$ dependence), without considering a species distribution 750 model or the ocean dynamics. Consequently, the presented results are model-dependent. The primary producer collapse is driven by the set of assessed species. To balance the lack of data to establish the tolerance patterns of species, only simulations including a high number of species (1000 or more) and/or different sets of marine biospheres would be more accurate to capture all patterns recorded in the fossil database. The K-Pg boundary is well known for extinctions of marine

755 species occupying the upper levels of the food chain, such as ammonites, belemnites, or marine reptiles. This study does not include any predator-prey model. In the absence of such links, we cannot explore potential extinctions of consumers due to cascading effects in the food web. This aspect is beyond the scope of this study, but this feedback should be tested in future models to determine why calcareous plankton were more severely affected by the mass extinction event than 760 other calcareous benthic organisms.

The simple model developed here to describe oceanic primary productivity is not yet an ecological model. However, for the first time in a long-term climate-carbon model, it introduces a retroaction between marine biodiversity and the long-term evolution of biogeochemical cycles. This 765 study introduces the development of more complex trophic chains featuring several levels of consumers.

Regarding the Chixculub impact, we do not explicitly consider the change in the light influx (i.e impact winter assumption by blocking out of sunlight) because marine organisms may present tolerance to a decline of light flux by increasing the size of organic structure absorbing photons 
770 (Geider et al. 1997). Consequently, the change of light influx has been considered by computing the primary productivity as a function of SST (see section 2.1). This assumption is based on measurements of photosynthetic rates derived from satellites (Behrenfeld and Falkowski, 1997 validity range -1 to $29^{\circ} \mathrm{C}$ ).

Finally, we cannot clearly assess the K-Pg transition without more precisely exploring

775 processes occurring over continents. Traces of acidification in lacustrine sediments (Font et al., 2016) and strong weathering related to volcanic pulses (Gertsch et al., 2011) suggest that the neutralisation reaction is not verified everywhere (i.e., sulphuric acid reacting with limestone), as defended by Maruoka and Koeberl (2003) and supported by the very low extinction rate of freshwater vertebrates (Sheehan and Fastovsky, 1992). Consequently, very strong acidification may

780 have occurred in rivers or restricted zones of the coastal ocean. In addition, evidence of very drastic climate changes over continents (Tobin et al., 2014) may also enhance extinction rates in the continental domain. Continental species should disappear more rapidly than marine organisms.

\section{Conclusion}

785

Using a coupled biodiversity-climate-carbon numerical model (ECO-GEOCLIM), we explored the triggering mechanisms of extinctions through the K-Pg boundary by quantifying the environmental effects on primary productivity, biomass, and biodiversity. We discovered two plausible pathways responsible for the K-Pg extinction. i) Due to the load of sulfate aerosols formed by the released of

790 sulfur (by the meteorite or by volcanic pulses), the abrupt cooling event decreases the consumption of the atmospheric carbon while the emissions are enhanced. Consequently the accumulation of atmospheric carbon is amplified and all the processes associated to inorganic carbon in the ocean are heavily perturbed ( $\mathrm{pH}$, alkalinity budget, calcite saturation...). ii) By the introduction of primary producers dependent on $\mathrm{pH}$ and sea surface temperatures, marine biomass declines due to oceanic 
795 disturbances despite the presence of nutrients. In response to the low percentage of residual living biomass, the burial of organic matter is weakened, and the atmospheric carbon dioxide increases.

Assuming a 10-km impactor, oceanic disturbances are characterised by an intense and brief cooling, spanning 10 years, driven by atmospheric S-aerosols. This brief cooling phase leads to a transient shutdown of the primary productivity. Whatever the pre-perturbation oceanic conditions

800 (Cretan or Neritan), surface oceans stay saturated with calcite $\left(\Omega_{\text {calcite }} \sim 1.3\right)$ despite acidification $(\Delta \mathrm{pH}-0.15)$ in open or coastal areas. Biotic losses for primary producers do not exceed $20 \%$, while ocean biomass is reduced by $60 \%(40 \%)$ for calcifying (noncalcifying) species. The discrepancy between biodiversity and biomass results from a collapse of a few calcifying species, accounting for most of the biomass.

805

When the emplacement of the Deccan Traps is considered, the surface ocean $\mathrm{pH}$ decreases by 0.2 , from 8.0 to 7.8 , while the deep ocean $\mathrm{pH}$ drops by 0.4 (from 7.8 to 7.4 ). This marine acidification is caused by the combination of long-term acidification triggered by the $\mathrm{CO}_{2}$ released by the Deccan Traps, coupled with short-term acidification resulting from the rainout of sulphate aerosols (Chicxulub). Succession of climate changes and marine acidification produces a dramatic

810 decrease of the oceanic biomass of calcifying species. Given the assumed sensitivity of marine organisms to abiotic factors ( $\Delta \mathrm{SST}$ and $\Delta \mathrm{pH})$, the biodiversity of calcifying species drops by about $80 \%$, while the biodiversity of noncalcifying species is reduced by about $60 \%$. This simulated mass extinction is supposed to be driven by the eruption of the Deccan Traps and amplified by the combination of $\mathrm{CO}_{2}$ and $\mathrm{SO}_{2}$ interplays and a sluggish organic carbon cycle. However, abrupt and

815 short-lived acidification caused by the Chicxulub impact may explain the severity of extinctions among pelagic calcifying species.

These findings may help us understand how an initial perturbation can be amplified, leading to mass extinction, but some cautions should be heeded. Despite a lack of data about sensitivity to abiotic factors of fossil species, all results presented in this study remain model-dependent because 820 only one set of theoretical species has been used, with all of them being primary producers. 
Moreover, these short-lived processes, acting as amplifying factors, become efficient only if the degassing is intense enough to overcome the silicate weathering buffering activity. Consequently, in the absence of a degassing scenario running over the whole K-Pg boundary period $(\sim 1 \mathrm{Ma})$, the present study is not able to capture some of the major features recorded before or in the aftermath of

825 the Deccan main phase.

acknowledgment :

CCRT, INSU Tellus SYSTER 2016 to BSM and GlH. 
Experimental set-up. Columns from left to right are: i) tested event: A for Asteroid scenario, D for Deccan traps and/or traps (both are defined as $\mathrm{CO}_{2}$ and $\mathrm{SO}_{2}$ emitted), ii) ocean state corresponds to carbonate cycle mode assumed (calcifying phytoplankton species versus other primary producer species), iii) biological feed-backs column indicates if species depend (or not) on abiotic environmental factors. D-Cretan-3 experiment presents a case where all other environmental factors remain efficient excepted seawater $\mathrm{pH}$. Eruption parameters for the Deccan traps have been explored. D-Cretan-linear has been performed with a linear degassing - loads of $\mathrm{CO}_{2}$ and $\mathrm{SO}_{2}$ held constant. D-Cretan-noSO 2 loads of $\mathrm{CO}_{2}$ held constant, $\mathrm{SO}_{2}$ emitted = 0. D-Cretan-longdegaz: load of gases held constant however the temporal spacing of eruptions has been doubled, which means that the length of the simulation is close to 400 kyrs.

It is noteworthy that all runs are performed with late Maastrichtian boundary conditions and a large number of species for primary producers (nveg=50). Reference runs (whatever ocean conditions) correspond to a carbon-climate equilibrium of $p \mathrm{CO}_{2} \sim 230 \mathrm{ppmv}$.

\begin{tabular}{|c|c|c|c|}
\hline Run & Tested geological event(s) & Ocean state & biological feed-backs \\
\hline Ref-Cretan & None & Cretan & yes \\
\hline Ref-Neritan & None & Neritan & yes \\
\hline A-Cretan-1 & Asteroid (10 km size) & Cretan & yes \\
\hline A-Cretan-2 & Asteroid (10 km size) & Cretan & yes \\
\hline A-Neritan & Asteroid (10 km size) & Neritan & yes \\
\hline D-Cretan-1 & Deccan traps & Cretan \\
\hline D-Cretan-2 & Deccan traps & Cretan & no effect cut-off \\
\hline D-Cretan-3 & Deccan traps & Cretan & yes \\
\hline D-Cretan-linear & Deccan traps (linear degassing) & Cretan & yes \\
\hline D-Cretan-noSO2 & Deccan traps (no SO2 emitted) & Cretan \\
\hline $\begin{array}{c}\text { D-Cretan- } \\
\text { longdegaz }\end{array}$ & $\begin{array}{c}\text { Deccan traps (temporal spacing of } \\
\text { eruptions has been doubled) }\end{array}$ & Cretan & yes \\
\hline D-Neritan & Deccan traps & Neritan & yes \\
\hline AD-Cretan-1 & Asteroid+Deccan traps & Cretan & yes \\
\hline AD-Cretan-1bis & Asteroid+Deccan traps (time- & Cretan & no \\
\hline AD-Cretan-2 & Asteroid+Deccan traps & Cretan & yes \\
\hline AD-Neritan & Asteroid+Deccan traps & Neritan & \\
\hline
\end{tabular}


Alegret, L., Thomas, E., Lohmann, K.C., 2012. End-Cretaceous marine mass extinction not caused by productivity collapse. Proc. Natl. Acad. Sci. 109, 728-732.

Barrera, E., Savin, S.M., 1999. Evolution of late Campanian-Maastrichtian marine climates and oceans. Spec. Pap.-Geol. Soc. Am. 245-282.

Bernaola, G., Monechi, S., 2007. Calcareous nannofossil extinction and survivorship across the Cretaceous- Paleogene boundary at Walvis Ridge (ODP Hole 1262C, South Atlantic Ocean). Palaeogeogr. Palaeoclimatol. Palaeoecol. 255, 132-156.

Besse, J., Courtillot, V., 2002. Apparent and true polar wander and the geometry of the geomagnetic field over the last 200 Myr. J. Geophys. Res. Solid Earth 107.

Bown, P., 2005. Selective calcareous nannoplankton survivorship at the Cretaceous-Tertiary boundary. Geology 33, 653-656. https://doi.org/10.1130/G21566AR.1

Bown, P.R., Lees, J.A., Young, J.R., 2004. Calcareous nannoplankton evolution and diversity through time, in: Coccolithophores. Springer, Berlin, Heidelberg, pp. 481-508. https://doi.org/10.1007/978-3-662-06278-4_18

Brady, P.V., Gíslason, S.R., 1997. Seafloor weathering controls on atmospheric CO2 and global climate. Geochim. Cosmochim. Acta 61, 965-973. https://doi.org/10.1016/S00167037(96)00385-7

Brugger, J., Feulner, G., Petri, S., 2017. Baby, it's cold outside: Climate model simulations of the effects of the asteroid impact at the end of the Cretaceous. Geophys. Res. Lett. 44, 419-427.

Caldeira, K., Rampino, M.R., 1990. Carbon dioxide emissions from Deccan volcanism and a K/T boundary greenhouse effect. Geophys. Res. Lett. 17, 1299-1302.

Charnay, B., Hir, G.L., Fluteau, F., Forget, F., Catling, D.C., 2017. A warm or a cold early Earth? New insights from a 3-D climate-carbon model. Earth Planet. Sci. Lett. 474, 97-109. https://doi.org/10.1016/j.eps1.2017.06.029

Chenet, A.L., Courtillot, V., Fluteau, F., Gérard, M., Quidelleur, X., Khadri, S.F.R., Subbarao, K.V., Thordarson, T., 2009. Determination of rapid Deccan eruptions across the CretaceousTertiary boundary using paleomagnetic secular variation : 2 . Constraints from analysis of eight new sections and synthesis for a 3500-m-thick composite section. J. Geophys. Res. Solid Earth 114. https://doi.org/10.1029/2008jb005644

Chenet, A.-L., Fluteau, F., Courtillot, V., Gérard, M., Subbarao, K.V., 2008. Determination of rapid 
Deccan eruptions across the Cretaceous-Tertiary boundary using paleomagnetic secular variation: Results from a 1200-m-thick section in the Mahabaleshwar escarpment. J. Geophys. Res. Solid Earth 113.

Chenet, A.-L., Quidelleur, X., Fluteau, F., Courtillot, V., Bajpai, S., 2007. 40K-40Ar dating of the Main Deccan large igneous province: Further evidence of KTB age and short duration. Earth Planet. Sci. Lett. 263, 1-15.

Collins, G.S., Melosh, H.J., Marcus, R.A., 2005. Earth impact effects program: A web-based computer program for calculating the regional environmental consequences of a meteoroid impact on Earth. Meteorit. Planet. Sci. 40, 817-840.

Coogan, L.A., Dosso, S.E., 2015. Alteration of ocean crust provides a strong temperature dependent feedback on the geological carbon cycle and is a primary driver of the Sr-isotopic composition of seawater. Earth Planet. Sci. Lett. 415, 38-46. https://doi.org/10.1016/j.eps1.2015.01.027

Courtillot, V., Besse, J., Vandamme, D., Montigny, R., Jaeger, J.-J., Cappetta, H., 1986. Deccan flood basalts at the Cretaceous/Tertiary boundary? Earth Planet. Sci. Lett. 80, 361-374. https://doi.org/10.1016/0012-821X(86)90118-4

Courtillot, V., Fluteau, F., 2014. A review of the embedded time scales of flood basalt volcanism with special emphasis on dramatically short magmatic pulses. Geol. Soc. Am. Spec. Pap. 505, SPE505-15.

Courtillot, V.E., Renne, P.R., 2003. On the ages of flood basalt events. Comptes Rendus Geosci. 335, 113-140. https://doi.org/10.1016/S1631-0713(03)00006-3

Dercourt, J., Ricou, L.E., Vrielynck, B., coopération, I. français du pétrole B. d'études industrielles et de, 1993. Atlas Tethys palaeoenvironmental maps. Paris : [Gauthier-Villars] : DiffusionCCGM.

Dessert, C., Dupré, B., François, L.M., Schott, J., Gaillardet, J., Chakrapani, G., Bajpai, S., 2001. Erosion of Deccan Traps determined by river geochemistry: impact on the global climate and the $87 \mathrm{Sr} / 86 \mathrm{Sr}$ ratio of seawater. Earth Planet. Sci. Lett. 188, 459-474. https://doi.org/10.1016/S0012-821X(01)00317-X

D’hondt, S., Donaghay, P., Zachos, J.C., Luttenberg, D., Lindinger, M., 1998. Organic carbon fluxes and ecological recovery from the Cretaceous-Tertiary mass extinction. Science 282, 276279.

D’Hondt, S., Pilson, M.E.Q., Sigurdsson, H., Hanson, A.K., Carey, S., 1994. Surface-water acidification and extinction at the Cretaceous-Tertiary boundary. Geology 22, 983-986. https://doi.org/10.1130/0091-7613(1994)022<0983:SWAAEA>2.3.CO;2 
Donnadieu, Y., Goddéris, Y., Bouttes, N., 2009. Exploring the climatic impact of the continental vegetation on the Mezosoic atmospheric CO2 and climate history. Clim. Past 5, 85-96.

Donnadieu, Y., Goddéris, Y., Pierrehumbert, R., Dromart, G., Fluteau, F., Jacob, R., 2006. A GEOCLIM simulation of climatic and biogeochemical consequences of Pangea breakup. Geochem. Geophys. Geosystems 7, Q11019. https://doi.org/10.1029/2006GC001278

Font, E., Carlut, J., Rémazeilles, C., Mather, T.A., Nédélec, A., Mirão, J., Casale, S., 2017. EndCretaceous akaganéite as a mineral marker of Deccan volcanism in the sedimentary record. Sci. Rep. 7, 11453. https://doi.org/10.1038/s41598-017-11954-y

Font, E., Ponte, J., Adatte, T., Fantasia, A., Florindo, F., Abrajevitch, A., Mirão, J., 2016. Tracing acidification induced by Deccan Phase 2 volcanism. Palaeogeogr. Palaeoclimatol. Palaeoecol., Impact, Volcanism, Global changes and Mass Extinctions 441, 181-197. https://doi.org/10.1016/j.palaeo.2015.06.033

Foster, G., Royer, D. and Lunt, D., 2017, Future climate forcing potentially without precedent in the last 420 million years, Nature Communications volume 8, Article number: 14845

Ganino, C., Arndt, N.T., 2009. Climate changes caused by degassing of sediments during the emplacement of large igneous provinces. Geology 37, 323-326.

Gardin, S., 2002. Late Maastrichtian to early Danian calcareous nannofossils at Elles (Northwest Tunisia). A tale of one million years across the $\mathrm{K}-\mathrm{T}$ boundary. Palaeogeogr. Palaeoclimatol. Palaeoecol. 178, 211-231.

Geider, R., MacIntyre, H., Kana, T. 1997, Dynamic model of phytoplankton growth and acclimation: Responses of the balanced growth rate and the chlorophyll a:carbon ratio to light, nutrient-limitation and temperature, Marine Ecology Progress Series 148(1-3):187-200 doi: $10.3354 /$ meps 148187

Gertsch, B., Keller, G., Adatte, T., Garg, R., Prasad, V., Berner, Z., Fleitmann, D., 2011. Environmental effects of Deccan volcanism across the Cretaceous-Tertiary transition in Meghalaya, India. Earth Planet. Sci. Lett. 310, 272-285. https://doi.org/10.1016/j.epsl.2011.08.015

Goddéris, Y., Joachimski, M.M., 2004. Global change in the Late Devonian: modelling the Frasnian-Famennian short-term carbon isotope excursions. Palaeogeogr. Palaeoclimatol. Palaeoecol. 202, 309-329. https://doi.org/10.1016/S0031-0182(03)00641-2

Gough, D.O., 1981. Solar interior structure and luminosity variations, in: Physics of Solar Variations. Springer, pp. 21-34.

Guidry, M.W., Mackenzie, F.T., 2000. Apatite weathering and the Phanerozoic phosphorus cycle. 
Geology 28, 631-634. https://doi.org/10.1130/0091-7613(2000)28<631:AWATPP>2.0.CO;2

Hay, W.W., 2004. Carbonate fluxes and calcareous nannoplankton, in: Coccolithophores. Springer, pp. 509-528.

Henehan, M.J., Hull, P.M., Penman, D.E., Rae, J.W.B., Schmidt, D.N., 2016. Biogeochemical significance of pelagic ecosystem function: an end-Cretaceous case study. Phil Trans R Soc B 371, 20150510. https://doi.org/10.1098/rstb.2015.0510

Henriksson, A.S., 1996. Calcareous nannoplankton productivity and succession across the Cretaceous-Tertiary boundary in the Pacific (DSDP Site 465) and Atlantic (DSDP Site 527) Oceans. Cretac. Res. 17, 451-477.

Herrmann, S., Thierstein, H.R., 2012. Cenozoic coccolith size changes_Evolutionary and/or ecological controls? Palaeogeogr. Palaeoclimatol. Palaeoecol. 333, 92-106.

Hull, P.M., Norris, R.D., Bralower, T.J., Schueth, J.D., 2011. A role for chance in marine recovery from the end-Cretaceous extinction. Nat. Geosci. 4, 856.

Jacob, R.L., 1997. Low frequency variability in a simulated atmosphere-ocean system. PhD Thesis 1698.

Kaiho, K., 1992. A low extinction rate of intermediate-water benthic foraminifera at the Cretaceous/Tertiary boundary. Mar. Micropaleontol. 18, 229-259.

Kaminski, E., Tait, S., Ferrucci, F., Martet, M., Hirn, B., Husson, P., 2011. Estimation of ash injection in the atmosphere by basaltic volcanic plumes: The case of the Eyjafjallajökull 2010 eruption. J. Geophys. Res. Solid Earth 116.

Keller, G., 2014. Deccan volcanism, the Chixculub impact, and the end-Cretaceous mass extinction : Coincidence ? Cause and effect ? Volcanism, Impacts, and Mass Extinctions: Causes and Effects. Geological Society of America, Boulder.

Kiessling, W., Flügel, E., Golonka, J., 2000. Fluctuations in the carbonate production of Phanerozoic reefs. Geol. Soc. Lond. Spec. Publ. 178, 191-215.

Kiessling, W., Flügel, E., Golonka, J.A.N., 2003. Patterns of Phanerozoic carbonate platform sedimentation. Lethaia 36, 195-225.

Krissansen-Totton, J., Catling, D.C., 2017. Constraining climate sensitivity and continental versus seafloor weathering using an inverse geological carbon cycle model. Nat. Commun. 8, 15423. https://doi.org/10.1038/ncomms 15423

Lefebvre, V., Donnadieu, Y., Goddéris, Y., Fluteau, F., Hubert-Théou, L., 2013. Was the Antarctic 
glaciation delayed by a high degassing rate during the early Cenozoic? Earth Planet. Sci. Lett. 371-372, 203-211. https://doi.org/10.1016/j.eps1.2013.03.049

Li, L., Keller, G., 1998. Abrupt deep-sea warming at the end of the Cretaceous. Geology 26, 995998.

Macleod, N., Rawson, P.F., Forey, P.L., Banner, F.T., Boudagher-Fadel, M.K., Bown, P.R., Burnett, J.A., Chambers, P., Culver, S., Evans, S.E., Jeffery, C., Kaminski, M.A., Lord, A.R., Milner, A.C., Milner, A.R., Morris, N., Owen, E., Rosen, B.R., Smith, A.B., Taylor, P.D., Urquhart, E., Young, J.R., 1997. The Cretaceous-Tertiary biotic transition. J. Geol. Soc. 154, 265-292. https://doi.org/10.1144/gsjgs.154.2.0265

Martin, R.E., 1995. Cyclic and secular variation in microfossil biomineralization: clues to the biogeochemical evolution of Phanerozoic oceans. Glob. Planet. Change 11, 1-23.

Martinez, I., Deutsch, A., Schärer, U., Ildefonse, P., Guyot, F., Agrinier, P., 1995. Shock recovery experiments on dolomite and thermodynamical calculations of impact induced decarbonation. J. Geophys. Res. Solid Earth 100, 15465-15476.

Maruoka, T., Koeberl, C., 2003. Acid-neutralizing scenario after the Cretaceous-Tertiary impact event. Geology 31, 489-492.

Miles, G.M., Grainger, R.G., Highwood, E.J., 2004. The significance of volcanic eruption strength and frequency for climate. Q. J. R. Meteorol. Soc. 130, 2361-2376.

Molina, E., Arenillas, I., Arz, J.A., 1998. Mass extinction in planktic Foraminifera at the Cretaceous/Tertiary boundary in subtropical and temperate latitudes. Bull. Société Géologique Fr. 169, 351-363.

Mussard, M., Le Hir, G., Fluteau, F., Lefebvre, V. and Goddéris, Y., 2014. Modeling the carbonsulfate interplays in climate changes related to the emplacement of continental flood basalts, Volcanism, Impacts, and Mass Extinctions: Causes and Effects. Geological Society of America, , pp. 339-352.

Ohno, S., Kadono, T., Kurosawa, K., Hamura, T., Sakaiya, T., Shigemori, K., Hironaka, Y., Sano, T., Watari, T., Otani, K., Matsui, T., Sugita, S., 2014. Production of sulphate-rich vapour during the Chicxulub impact and implications for ocean acidification. Nat. Geosci. 7, 279. https://doi.org/10.1038/ngeo2095

Oliva, P., Viers, J., Dupré, B., 2003. Chemical weathering in granitic environments. Chem. Geol. $202,225-256$. 
Petersen, S.V., Dutton, A., Lohmann, K.C., 2016. End-Cretaceous extinction in Antarctica linked to both Deccan volcanism and meteorite impact via climate change. Nat. Commun. 7, 12079. https://doi.org/10.1038/ncomms12079

Pierazzo, E., Hahmann, A.N., Sloan, L.C., 2003. Chicxulub and Climate: Radiative Perturbations of Impact-Produced S-Bearing Gases. Astrobiology 3, 99-118. https://doi.org/10.1089/153110703321632453

Pierazzo, E., Kring, D.A., Melosh, H.J., 1998. Hydrocode simulation of the Chicxulub impact event and the production of climatically active gases. J. Geophys. Res. Planets 103, 28607-28625.

Prinn, R.G and Fegley, B., Bolide impacts, 1987. Acid rain, and biospheric trauams at the Cretaceous-Tertiary boundary. Earth and Planetary Science Letters, 83 (1987) 1 - 15

Punekar, J., Mateo, P., Keller, G., Keller, G., 2014. Effects of Deccan volcanism on paleoenvironment and planktic foraminifera: A global survey. Geol. Soc. Am. Spec. Pap. 505. https://doi.org/10.1130/2014.2505(04)

Quere, C.L., Harrison, S.P., Colin Prentice, I., Buitenhuis, E.T., Aumont, O., Bopp, L., Claustre, H., Cotrim Da Cunha, L., Geider, R., Giraud, X., 2005. Ecosystem dynamics based on plankton functional types for global ocean biogeochemistry models. Glob. Change Biol. 11, 20162040.

Renne, P.R., Deino, A.L., Hilgen, F.J., Kuiper, K.F., Mark, D.F., Mitchell, W.S., Morgan, L.E., Mundil, R., Smit, J., 2013. Time scales of critical events around the Cretaceous-Paleogene boundary. Science 339, 684-687.

Renne, P.R., Sprain, C.J., Richards, M.A., Self, S., Vanderkluysen, L., Pande, K., 2015. State shift in Deccan volcanism at the Cretaceous-Paleogene boundary, possibly induced by impact. Science 350, 76-78.

Robock, A., Ammann, C.M., Oman, L., Shindell, D., Levis, S., Stenchikov, G., 2009. Did the Toba volcanic eruption of $74 \mathrm{ka} \mathrm{BP}$ produce widespread glaciation? J. Geophys. Res. Atmospheres 114.

Royer D., 2006. $\mathrm{CO}_{2}$-forced climate thresholds during the Phanerozoic, Geochimica et Cosmochimica Acta, 70(23), 5665-5675 doi.org/10.1016/j.gca.2005.11.031

Schmidt, A., Skeffington, R.A., Thordarson, T., Self, S., Forster, P.M., Rap, A., Ridgwell, A., Fowler, D., Wilson, M., Mann, G.W., Wignall, P.B., Carslaw, K.S., 2016. Selective environmental stress from sulphur emitted by continental flood basalt eruptions. Nat. Geosci. 9, 77. https://doi.org/10.1038/ngeo2588

Schöbel, S., de Wall, H., Ganerød, M., Pandit, M.K., Rolf, C., 2014. Magnetostratigraphy and 
40Ar-39Ar geochronology of the Malwa Plateau region (Northern Deccan Traps), central western India: Significance and correlation with the main Deccan Large Igneous Province sequences. J. Asian Earth Sci. 89, 28-45.

Schoene, B., Samperton, K., Eddy, M., Keller, G., Adatte, T., Bowring, S., Khadri, S., GERTSCH, B., 2015. U-Pb geochronology of the Deccan Traps and relation to the end-Cretaceous mass extinction. Science 347, 182-184. https://doi.org/10.1126/science.aaa0118

Schoene, B., Eddy, M., Samperton, K., Keller,B., Keller, G., Adatte,T., Khadri, S. 2019, U-Pb constraints on pulsed eruption of the Deccan Traps across the end-Cretaceous mass extinction. Science 363, doi: 10.1126/science.aau2422

Self, S., 2006. The effects and consequences of very large explosive volcanic eruptions. Philos. Trans. R. Soc. Lond. Math. Phys. Eng. Sci. 364, 2073-2097.

Self, S., Blake, B., Sharma, K., Widdowson, M, Sephton, S. 2008, Sulfur and Chlorine in Late Cretaceous Deccan Magmas and Eruptive Gas Release, Sciences, 3195870):1654-7 doi :10.1126/science. 1152830

Semtner, A.J., 1976. A Model for the Thermodynamic Growth of Sea Ice in Numerical Investigations of Climate. J. Phys. Oceanogr. 6, 379-389. https://doi.org/10.1175/15200485(1976)006<0379:AMFTTG>2.0.CO;2

Sepúlveda, J., Wendler, J.E., Summons, R.E., Hinrichs, K.-U., 2009. Rapid resurgence of marine productivity after the Cretaceous-Paleogene mass extinction. Science 326, 129-132.

Sheehan, P.M., Fastovsky, D.E., 1992. Major extinctions of land-dwelling vertebrates at the Cretaceous-Tertiary boundary, eastern Montana. Geology 20, 556-560.

Sitch, S., Smith, B., Prentice, I.C., Arneth, A., Bondeau, A., Cramer, W., Kaplan, J.O., Levis, S., Lucht, W., Sykes, M.T., 2003. Evaluation of ecosystem dynamics, plant geography and terrestrial carbon cycling in the LPJ dynamic global vegetation model. Glob. Change Biol. 9, 161-185.

Sprain, C., Renne, P., Vanderkluysen, L., Pande, K., Self, S., Mittal, T. 2019, The eruptive tempo of Deccan volcanism in relation to the Cretaceous-Paleogene boundary. Science 363, 866. doi: $10.1126 /$ science.aav1446

Stanley, S.M., Hardie, L.A., 1998. Secular oscillations in the carbonate mineralogy of reef-building and sediment-producing organisms driven by tectonically forced shifts in seawater chemistry. Palaeogeogr. Palaeoclimatol. Palaeoecol. 144, 3-19.

Steuber, T., 2002. Plate tectonic control on the evolution of Cretaceous platform-carbonate 
production. Geology 30, 259-262.

Thibault, N., Galbrun, B., Gardin, S., Minoletti, F., Le Callonnec, L., 2016. The end-Cretaceous in the southwestern Tethys (Elles, Tunisia): orbital calibration of paleoenvironmental events before the mass extinction. Int. J. Earth Sci. 105, 771-795.

Thibault, N., Husson, D., 2016. Climatic fluctuations and sea-surface water circulation patterns at the end of the Cretaceous era: Calcareous nannofossil evidence. Palaeogeogr. Palaeoclimatol. Palaeoecol. 441, 152-164.

Timmreck, C., 2012. Modeling the climatic effects of large explosive volcanic eruptions. Wiley Interdiscip. Rev. Clim. Change 3, 545-564.

Tobin, T.S., Bitz, C.M., Archer, D., 2017. Modeling climatic effects of carbon dioxide emissions from Deccan Traps volcanic eruptions around the Cretaceous-Paleogene boundary. Palaeogeogr. Palaeoclimatol. Palaeoecol., Mass Extinction Causality: Records of Anoxia, Acidification, and Global Warming during Earth's Greatest Crises 478, 139-148. https://doi.org/10.1016/j.palaeo.2016.05.028

Tobin, T.S., Wilson, G.P., Eiler, J.M., Hartman, J.H., 2014. Environmental change across a terrestrial Cretaceous-Paleogene boundary section in eastern Montana, USA, constrained by carbonate clumped isotope paleothermometry. Geology 42, 351-354.

Tyrrell, T., Merico, A., McKay, D.I.A., 2015. Severity of ocean acidification following the endCretaceous asteroid impact. Proc. Natl. Acad. Sci. 112, 6556-6561. https://doi.org/10.1073/pnas.1418604112

Vellekoop, J., Sluijs, A., Smit, J., Schouten, S., Weijers, J.W., Damsté, J.S.S., Brinkhuis, H., 2014. Rapid short-term cooling following the Chicxulub impact at the Cretaceous-Paleogene boundary. Proc. Natl. Acad. Sci. 111, 7537-7541.

Walker, L., Wilkinson, B.H., and Ivany, L.C. 2002.Continental Drift and Phanerozoic Carbonate Accumulation in Shallow-Shelf and Deep-Marine Settings. Journal of Geology 110(75-87), doi : $10.1086 / 324318$

Wallmann, K., 2001. Controls on the cretaceous and cenozoic evolution of seawater composition, atmospheric CO2 and climate. Geochim. Cosmochim. Acta 65, 3005-3025. https://doi.org/10.1016/S0016-7037(01)00638-X

Ward, W.C., Keller, G., Stinnesbeck, W., Adatte, T., 1995. Yucatán subsurface stratigraphy: Implications and constraints for the Chicxulub impact. Geology 23, 873-876. 
Wignall, P.B., 2001. Large igneous provinces and mass extinctions. Earth-Sci. Rev. 53, 1-33. https://doi.org/10.1016/S0012-8252(00)00037-4

Woelders, L., Vellekoop, J., Kroon, D., Smit, J., Casadío, S., Prámparo, M. B., Speijer, R. P. 865 (2017). Latest Cretaceous climatic and environmental change in the South Atlantic region. Paleoceanography, 32(5), 466-483. doi: 10.1002/2016PA003007

Zachos, J.C., Arthur, M.A., Dean, W.E., 1989. Geochemical evidence for suppression of pelagic marine productivity at the Cretaceous/Tertiary boundary. Nature 337, 61 .

Zeebe, R.E., Westbroek, P., 2003. A simple model for the $\mathrm{CaCO} 3$ saturation state of the ocean: The "Strangelove," the "Neritan," and the "Cretan" Ocean. Geochem. Geophys. Geosystems 4 
Figure 1. Atmospheric carbon dioxide and surface seawater changes caused by Chicxulub impact. Red curves are attributed to A-Cretan-1 case, black ones to A-Cretan-2.

Both simulations start from identical initial conditions : Ref-Cretan (pCO2 init $230 \mathrm{ppmv})$.

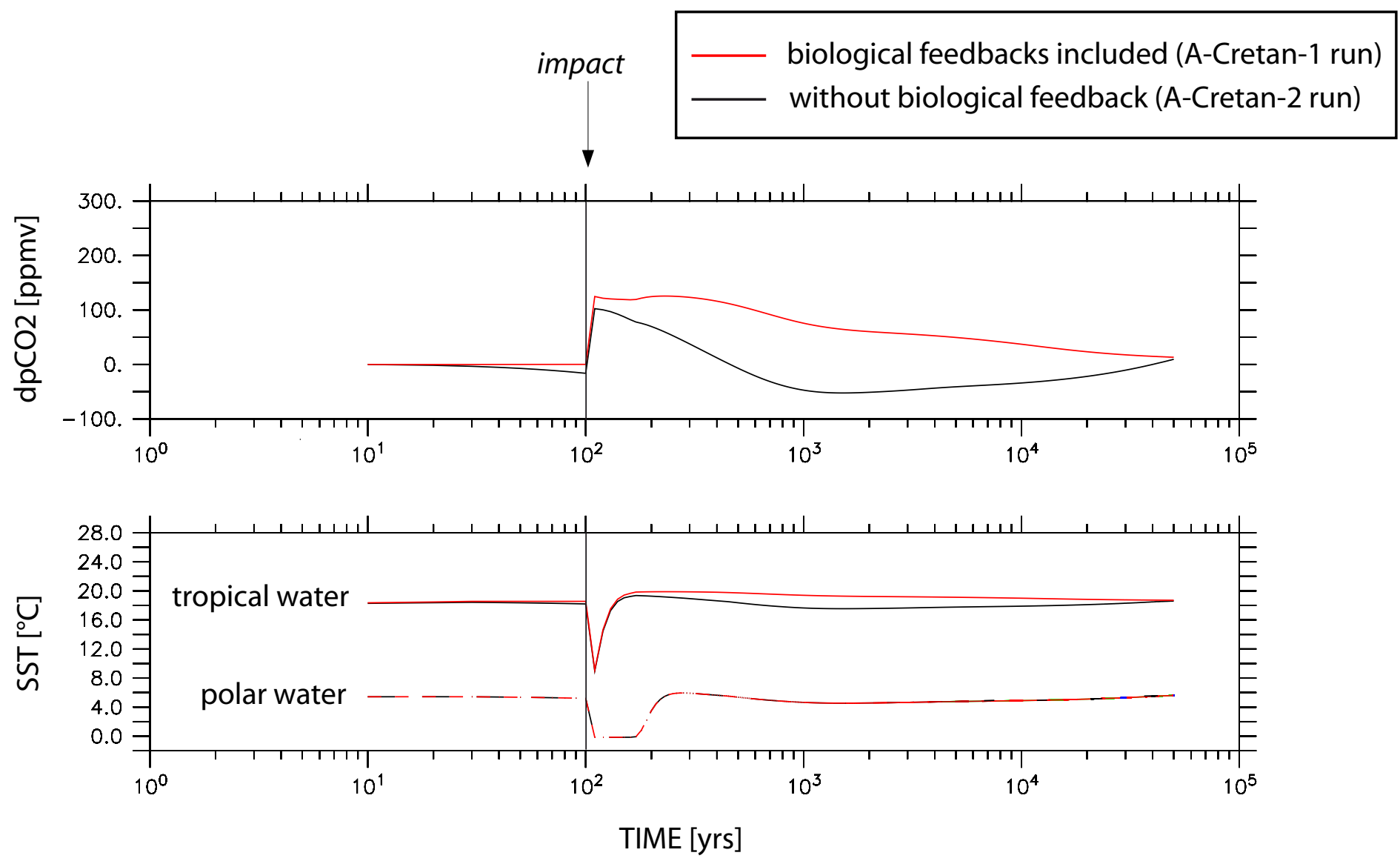


Figure 2. a) world wide primary productivity and b) phophorus content (surface ocean) simulated for the Chicxulub impact

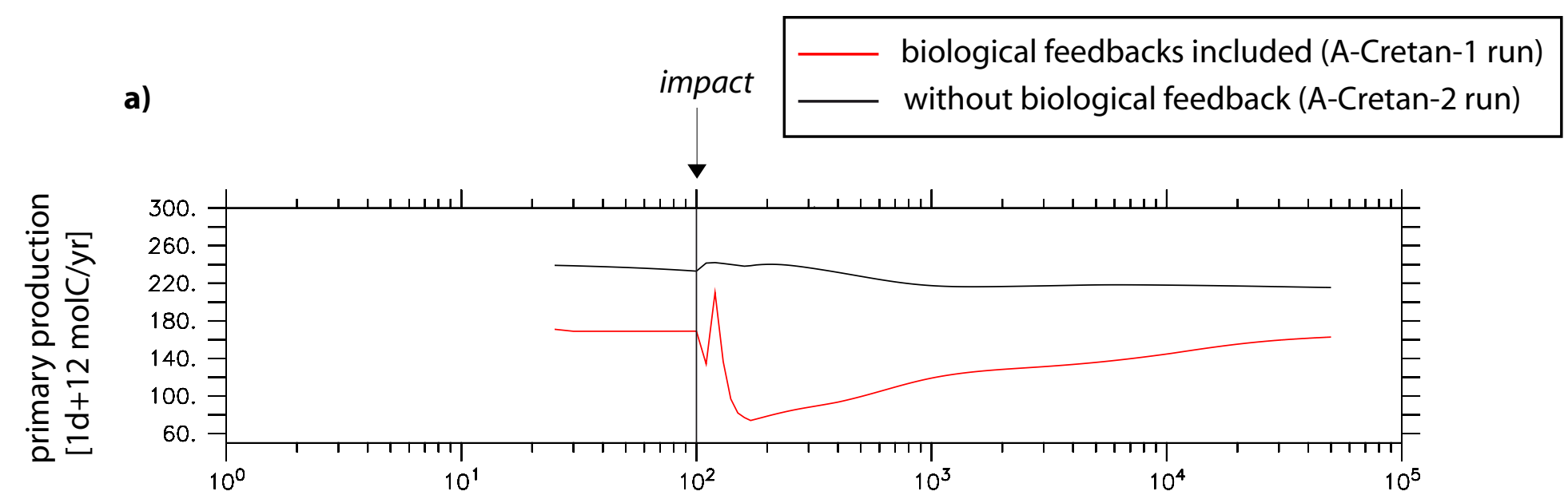

b)

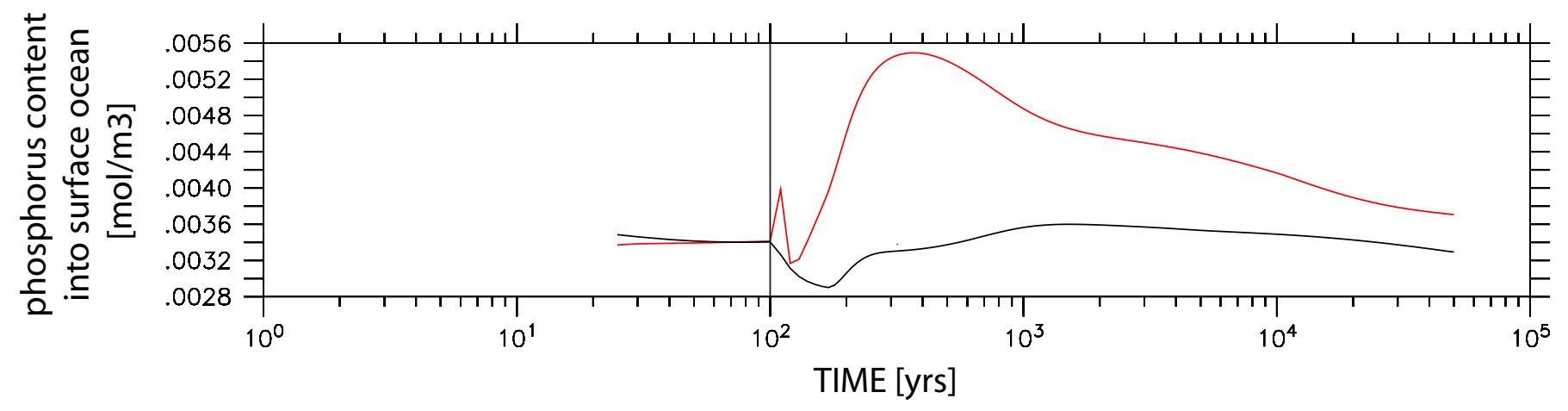


Figure 3: ocean perturbations induced by the Chicxulub impact.

2 states of ocean : Neritan (blue lines) versus Cretan (red lines), are considered.

$\mathrm{pH}$ evolutions simulated for $\mathbf{a})$ surface versus deep ocean, $\mathbf{b}$ ) open versus coastal ocean.

c) calcite saturation state for surface ocean compared to deep ocean.

d) carbonates precipitation changes for pelagic versus nereitic environment.

e) global alkalinity of the ocean compared to the coastal tropical ocean.

a) surface ocean (continous line) vs deep ocean (dashed line)

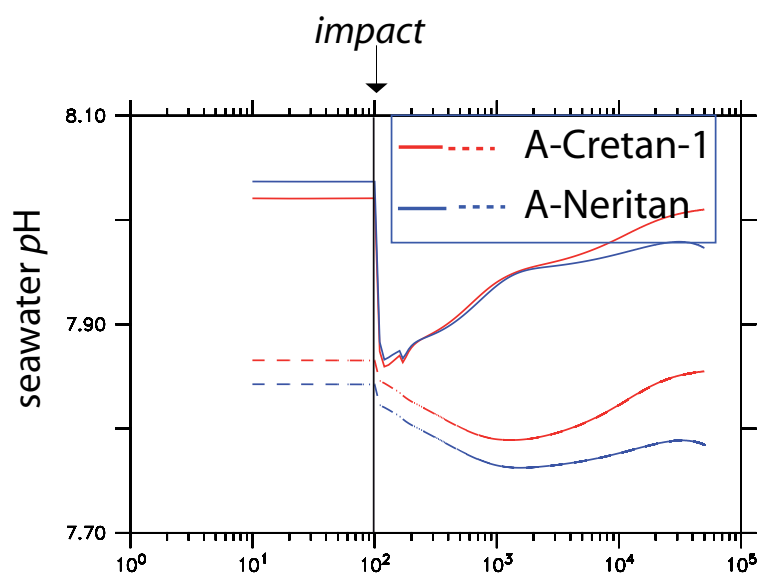

b) open ocean (continous line) vs coastal ocean (dashed line)

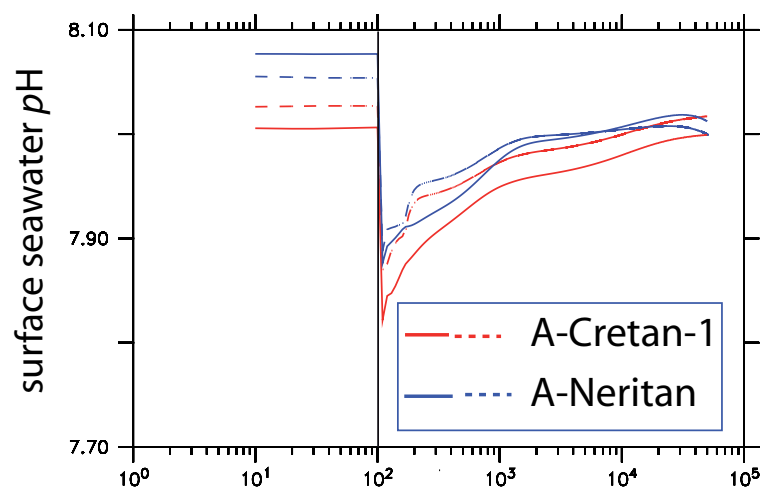

c) surface ocean (continous line) vs deep water (dashed line)

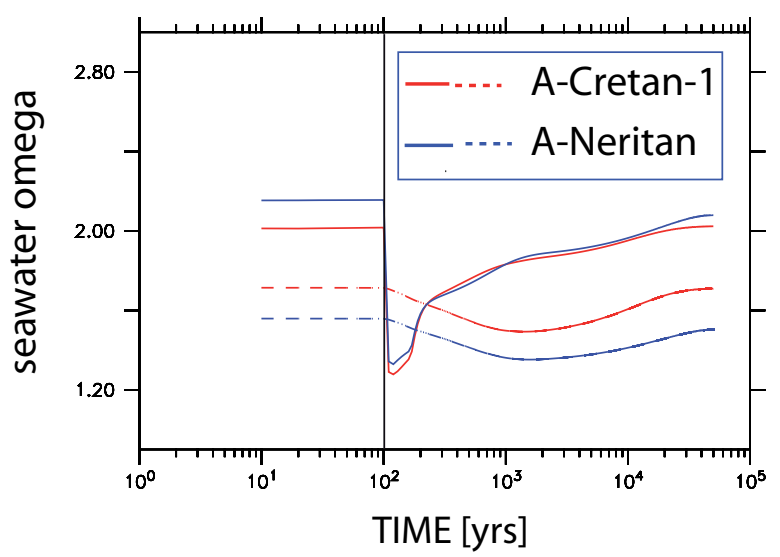

d) pelagic (thick line ) vs neritic (thin line)

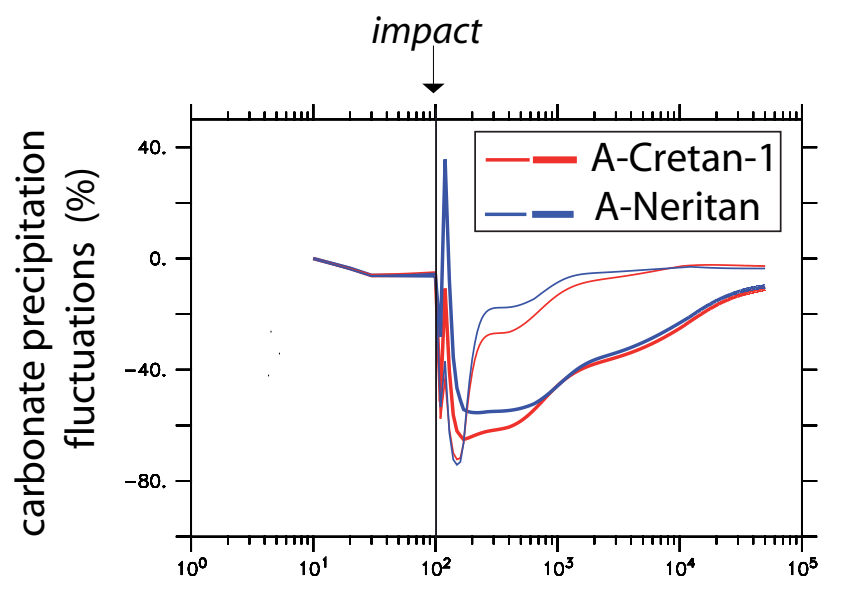

e) global alkalinity (black curve) vs coastal ocean (red)

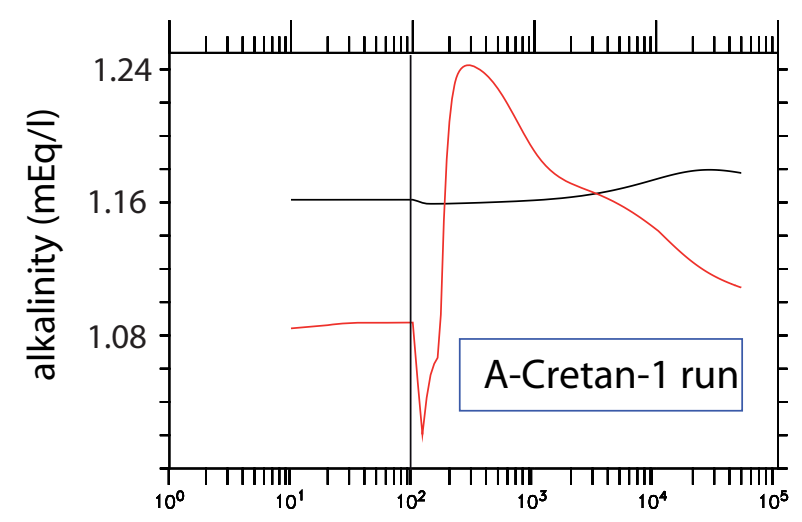

f) carbonates weathered $\left(\mathrm{cw}_{0}=2.010^{12} \mathrm{molC} / \mathrm{yr}\right)$ vs silicates $\left(\mathrm{sw}_{0}=5.310^{12} \mathrm{molC} / \mathrm{yr}\right)$

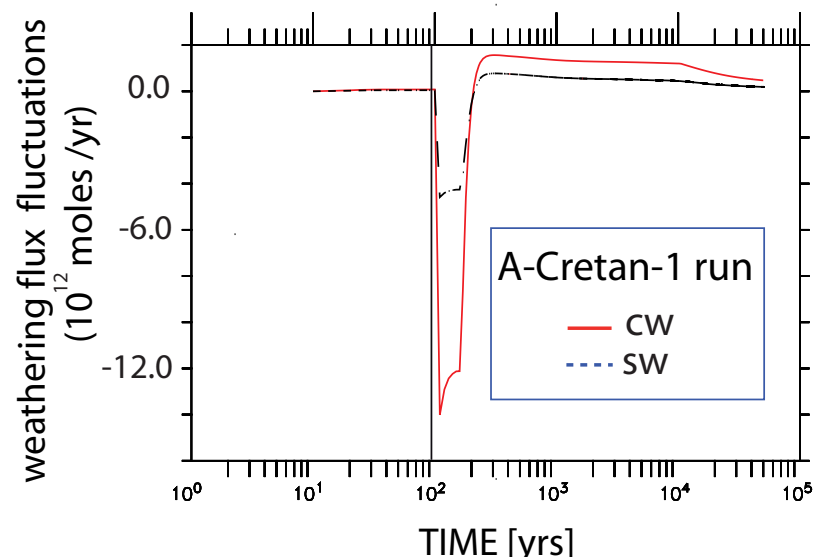


Figure 4. Biomass and mass extinction ratio(ME ratio) induced by the Chicxulub impact

a) for noncalcifying (upper panels) - coloured lines represent PFTs

b) calcifying primary producers (lower panels).

a) pelagic noncalcifying primary producers (open ocean - mid and low latitudes)
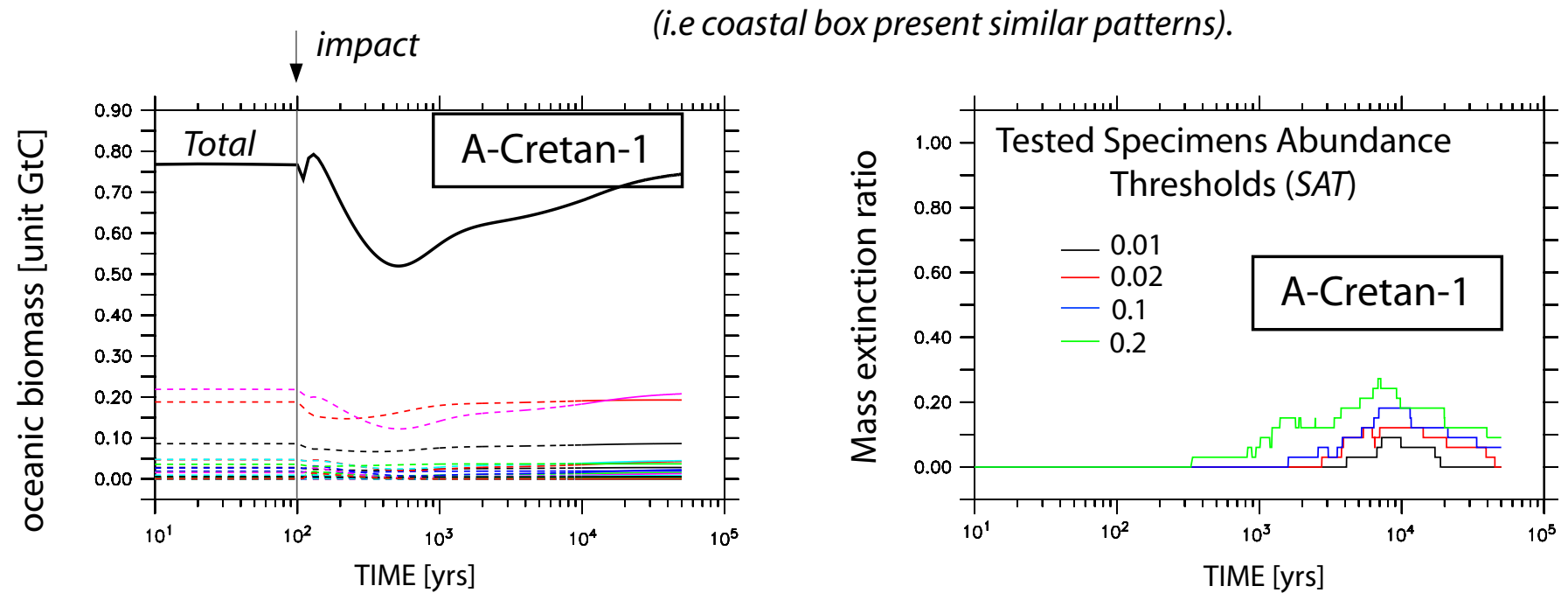

b) pelagic calcifying primary producers (open ocean - mid and low latitudes)
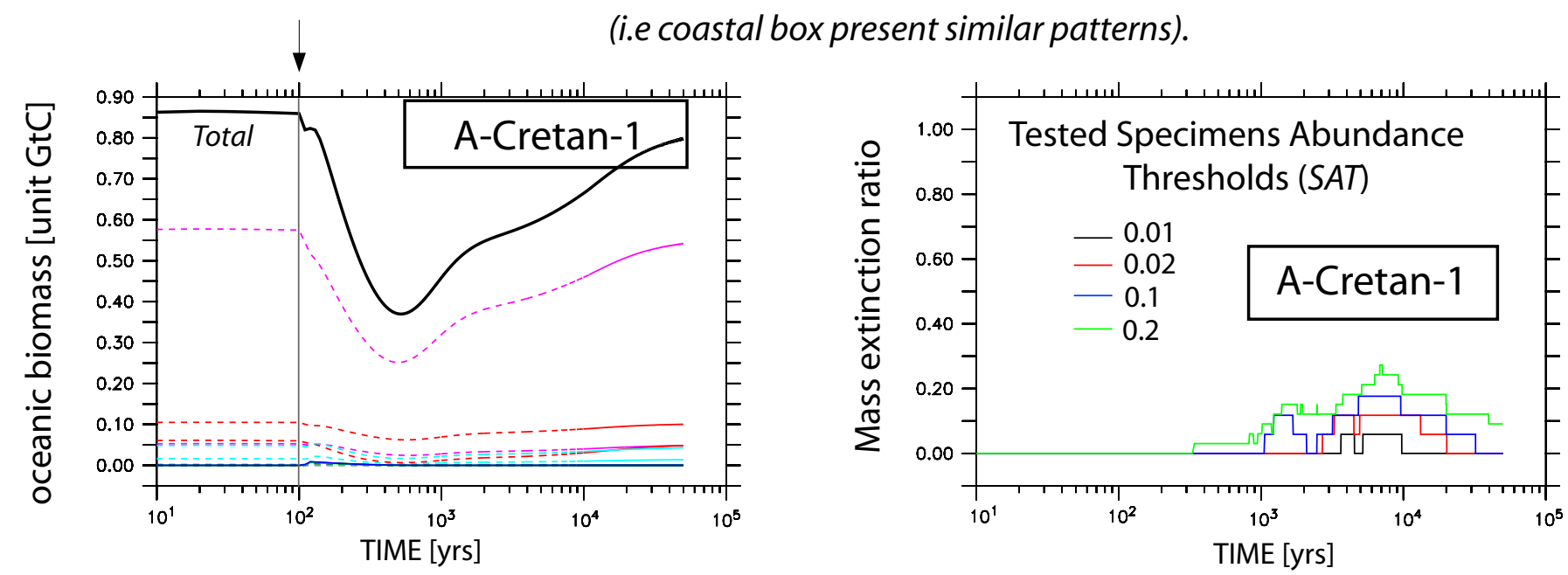
Figure 5 : Rise of atmospheric carbon dioxide and the corresponding dSST. dSST are presented at different time-scale for showing long-term warming interrupted by short-lived cooling events. Grey band represents the deccan traps (main phase)
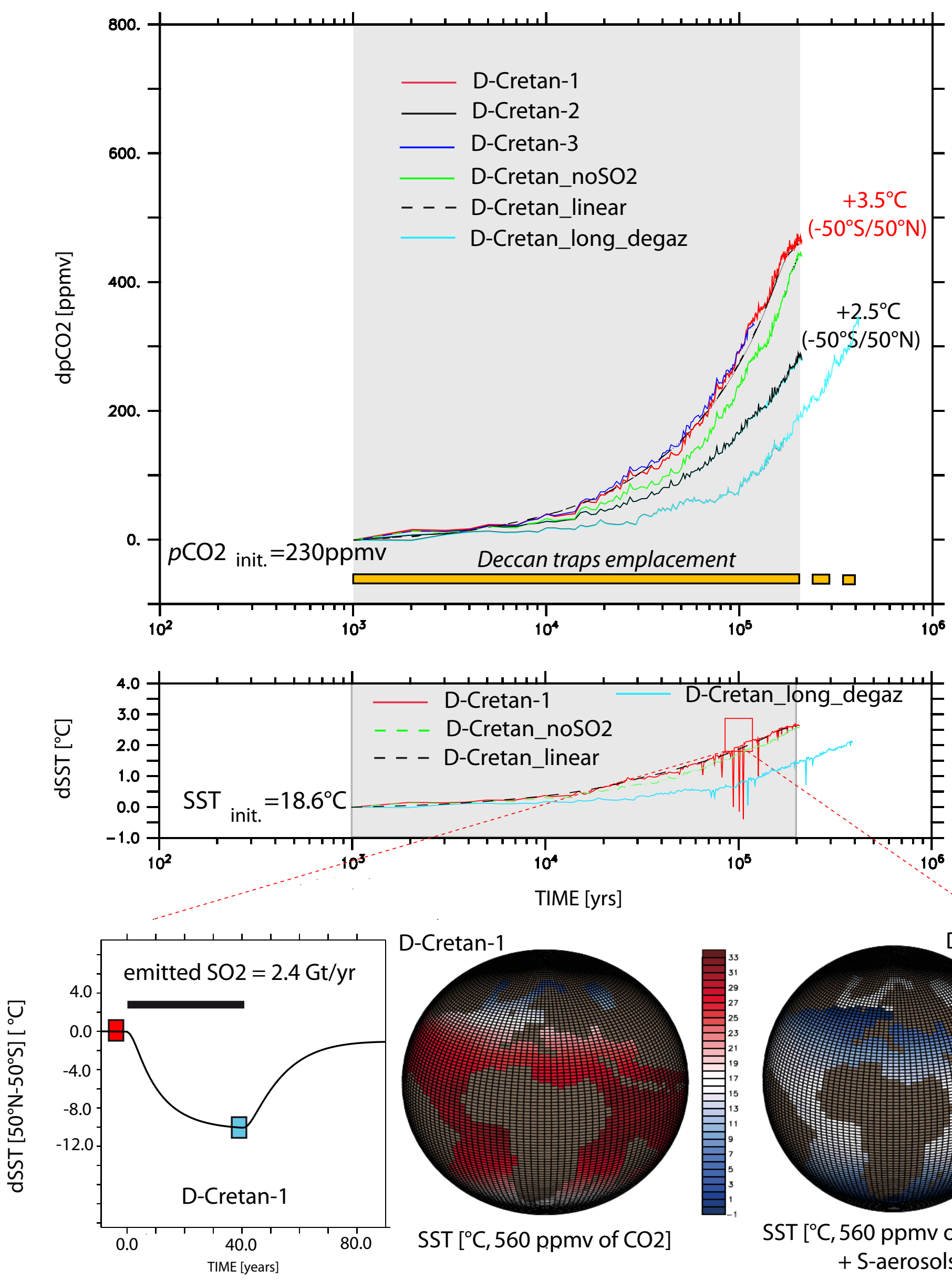

D-Cretan-1

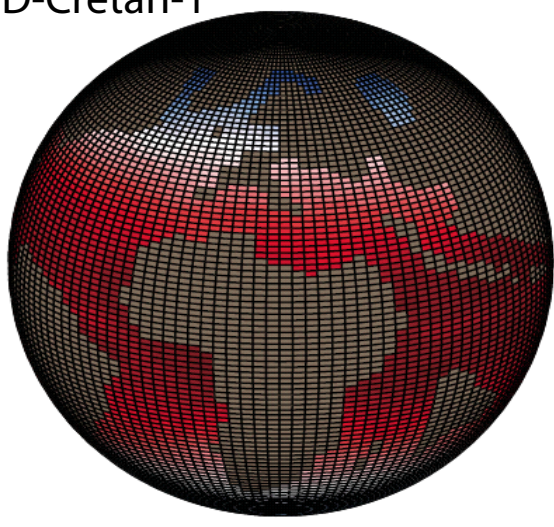

$\mathrm{SST}\left[{ }^{\circ} \mathrm{C}, 560 \mathrm{ppmv}\right.$ of $\left.\mathrm{CO} 2\right]$
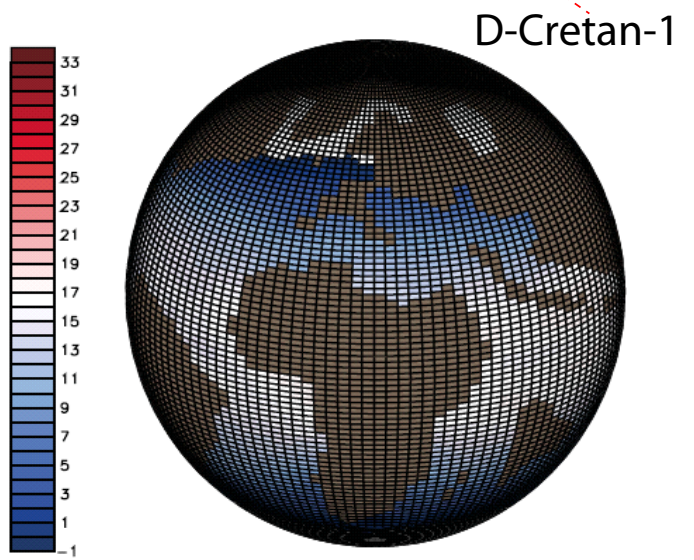

SST $\left[{ }^{\circ} \mathrm{C}, 560\right.$ ppmv of $\left.\mathrm{CO} 2\right]$ + S-aerosols 
Figure 6: ocean perturbations induced by Deccan traps emplacement.

2 states of ocean : Neritan (blue lines) versus Cretan (red lines), are considered.

$p \mathrm{H}$ evolutions simulated for $\mathbf{a}$ ) surface versus deep ocean, $\mathbf{b}$ ) open versus coastal ocean.

c) calcite saturation state for surface ocean compared to deep ocean, and d) lysocline depth evolution.

a) surface ocean (contineous line) vs deep water (dashed line)

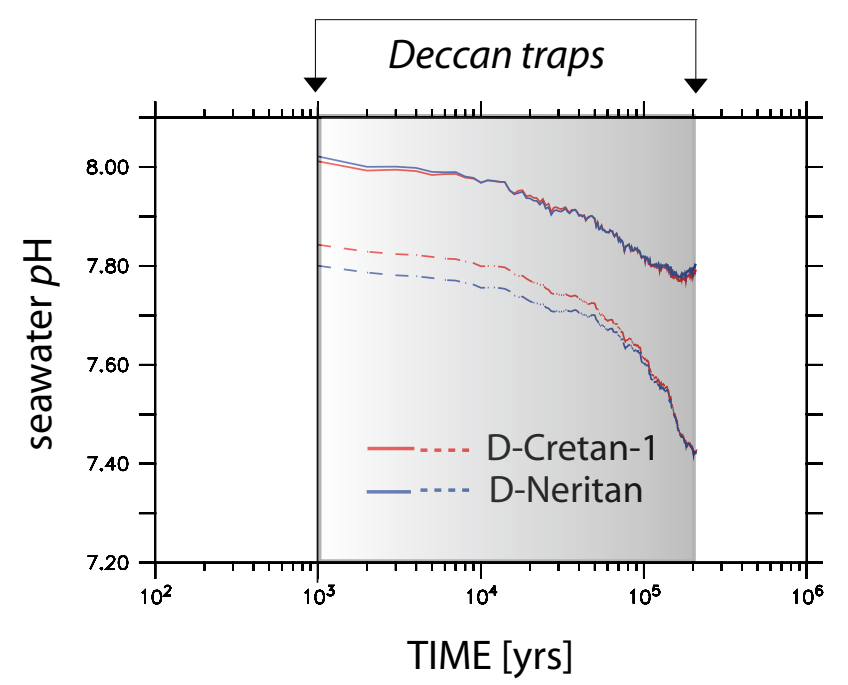

c) surface ocean (contineous line) vs deep water (dashed line)

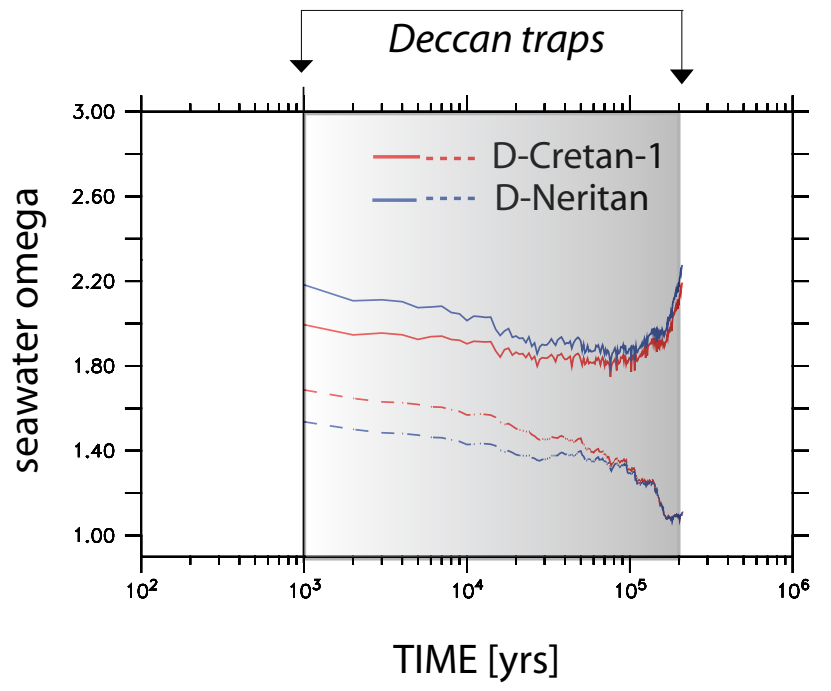

b) open ocean (contineous line) vs coastal ocean (dashed line)

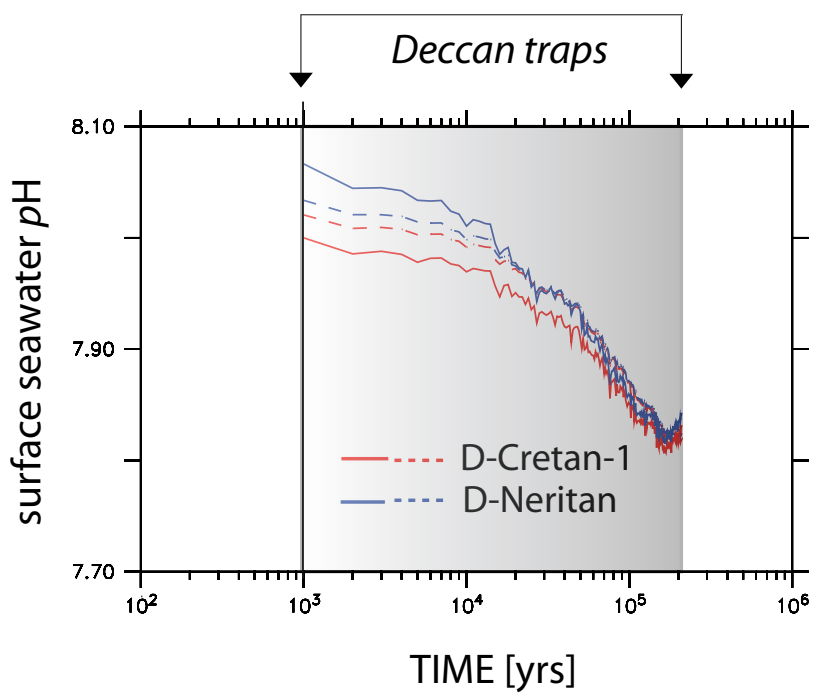

d) lysocline depth evolution

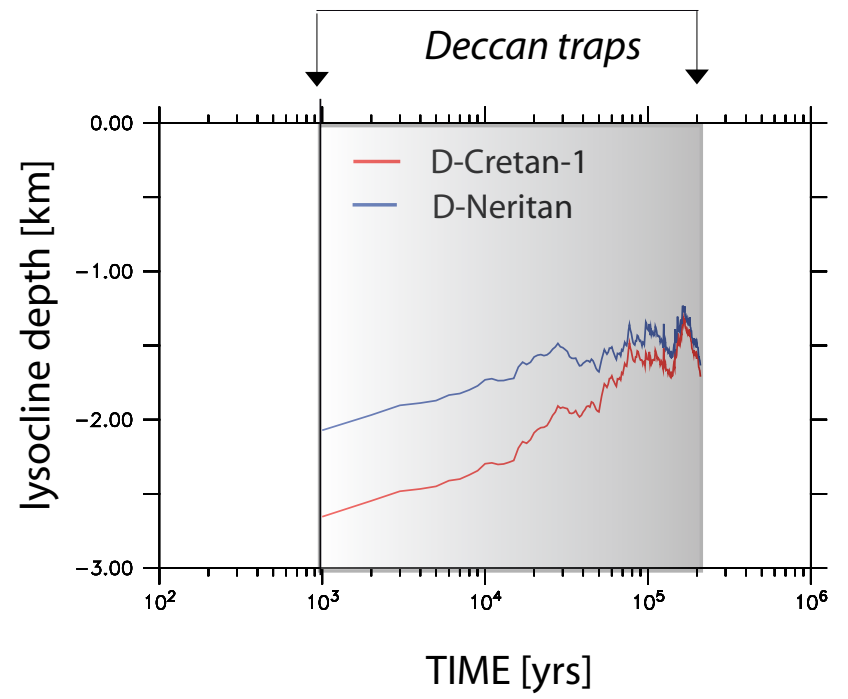


Figure 7. Biomass and mass extinction ratio(ME ratio) induced by Deccan traps

a) for noncalcifying (upper panels) - coloured lines represent PFTs

b) calcifying primary producers (lower panels).

a) pelagic noncalcifying primary producers (open ocean - mid and low latitudes)

coastal boxes present similar patterns.
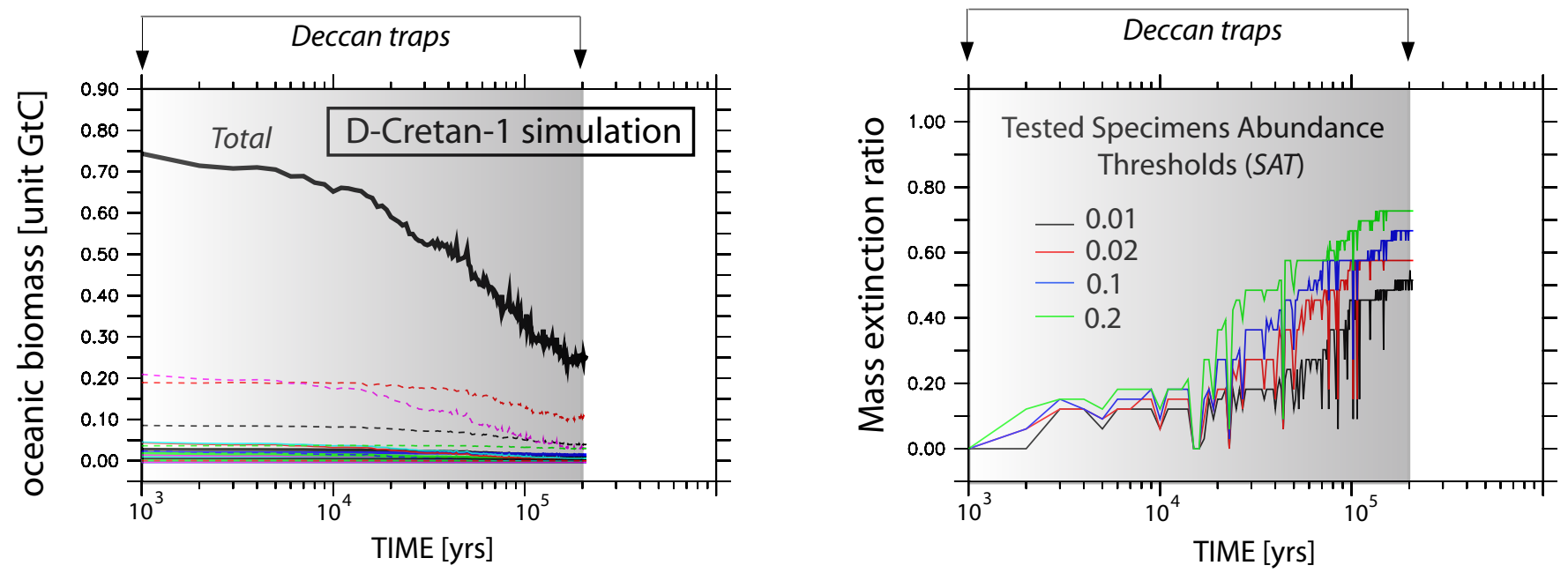

b) pelagic calcifying primary producers (open ocean - mid and low latitudes) coastal boxes present similar patterns.
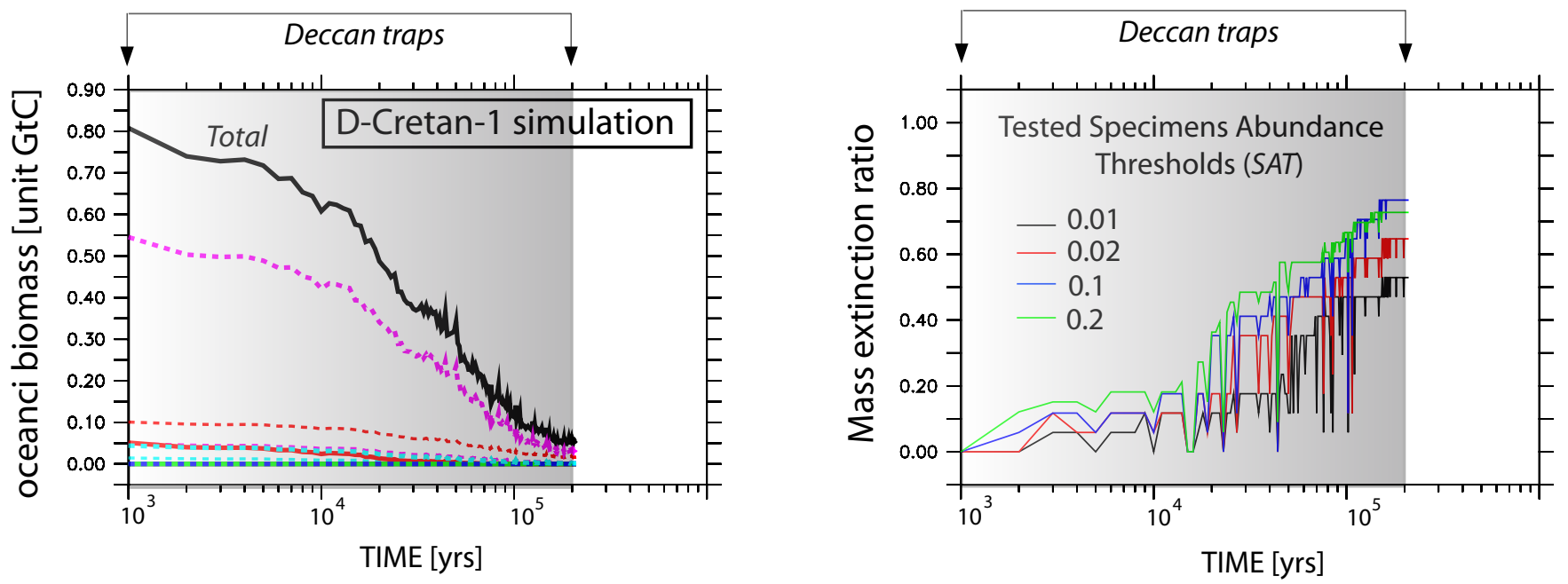
figure 8. Relative changes for a) world wilde primary productivity and b) phophorus content (upper ocean) simulated for Deccan traps

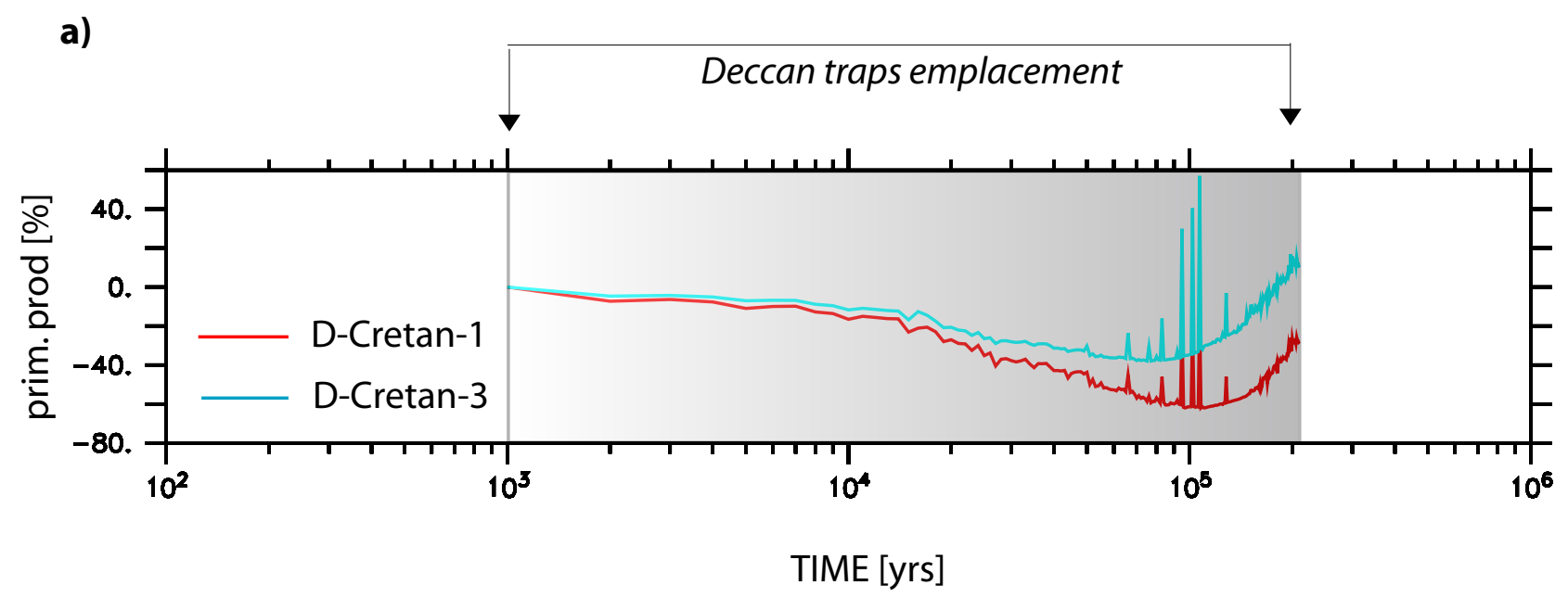

b)

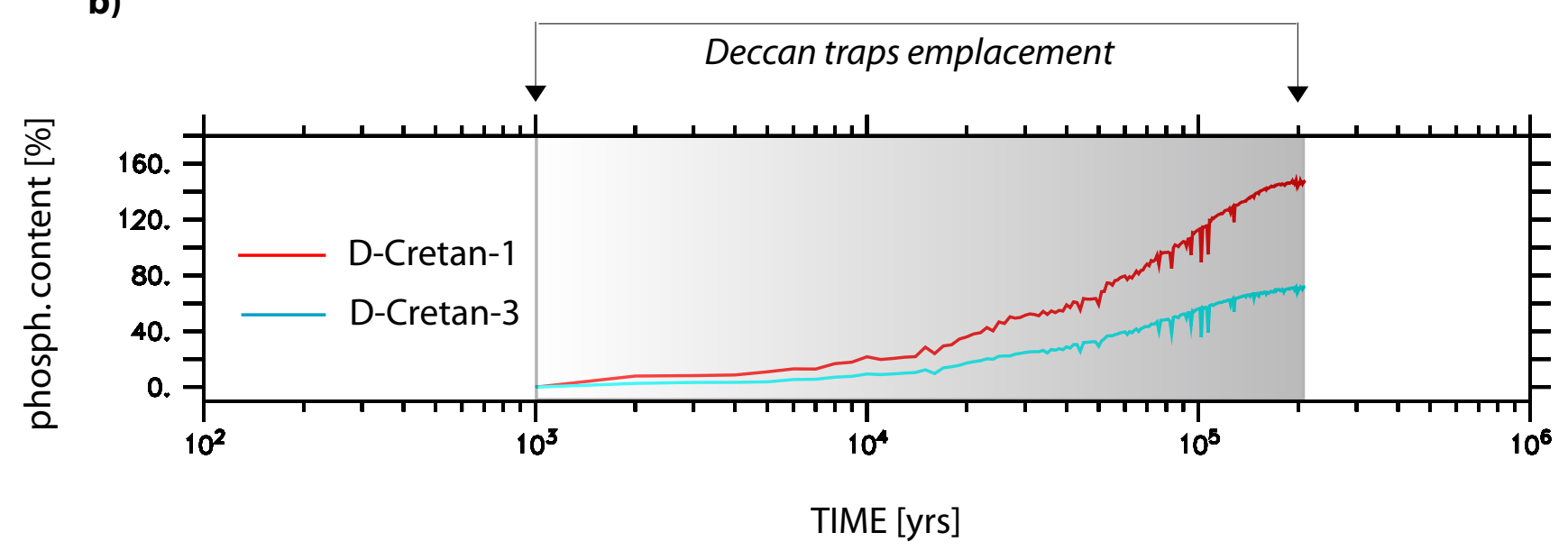


Figure 9. from a) to c) AD-Cretan-1 simulation compared to AD-Neritan, contineous line (surface o vs dashed line (deep water). Panels d) and e) presents calcifying/noncalcifying perturbat for AD-Cretan-1 run.

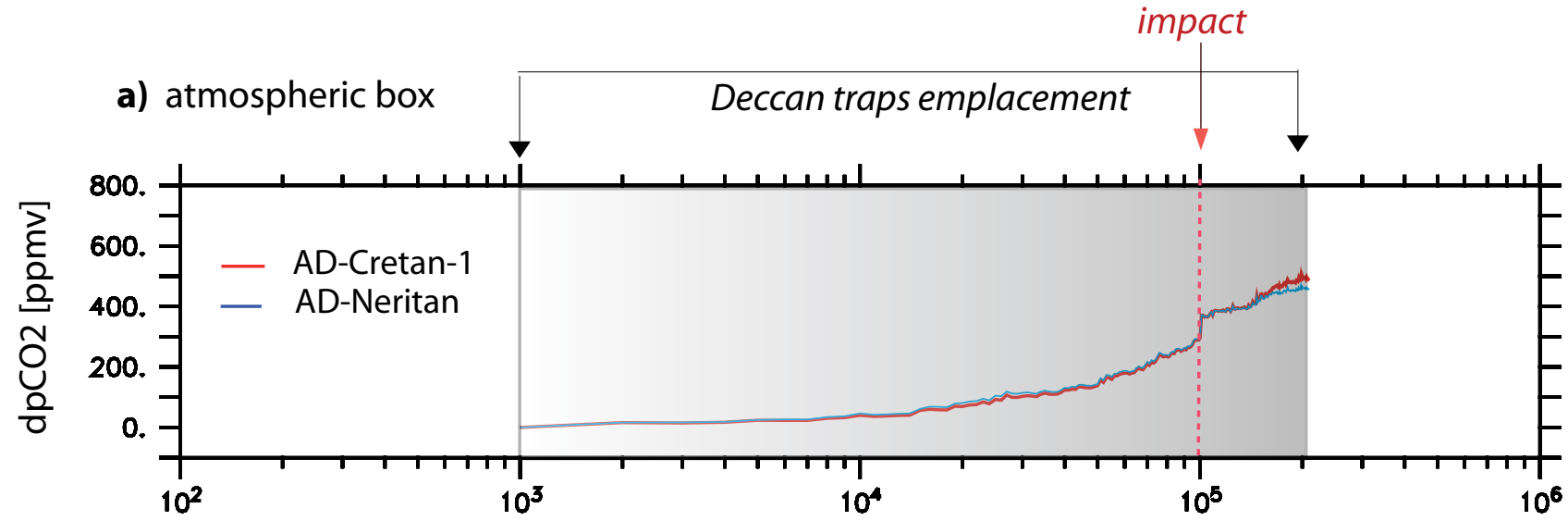

b) oceanic boxes (from low to mid latitudes)

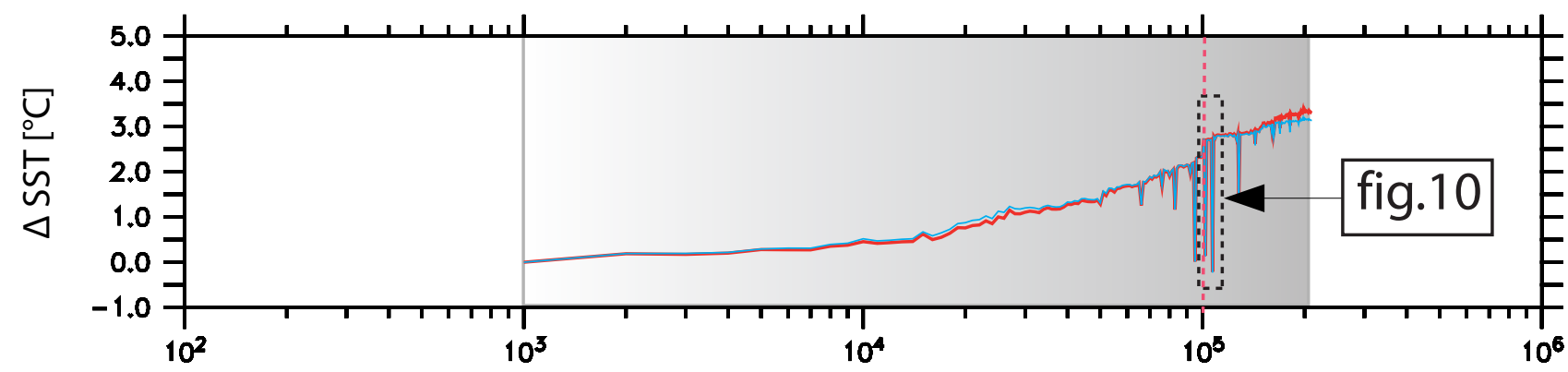

c) oceanic boxes (from low to mid latitudes)

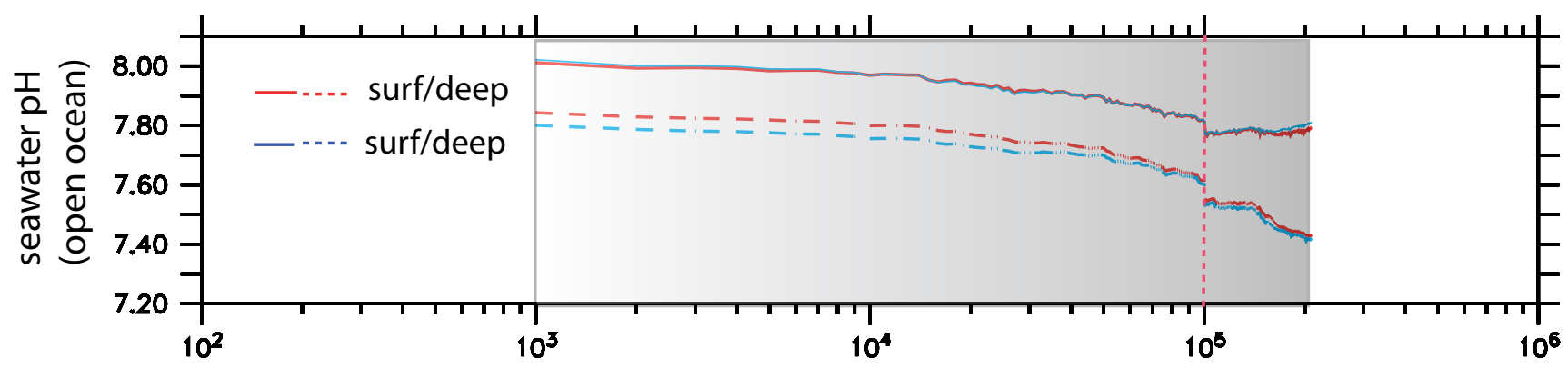

d) oceanic boxes (from low to mid latitudes)

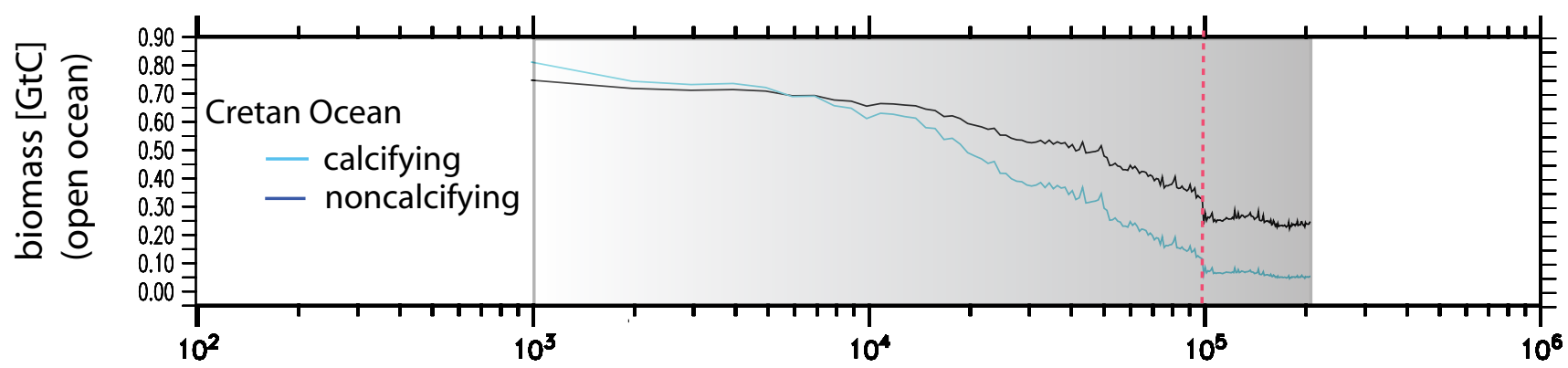

e) oceanic boxes (from low to mid latitudes)

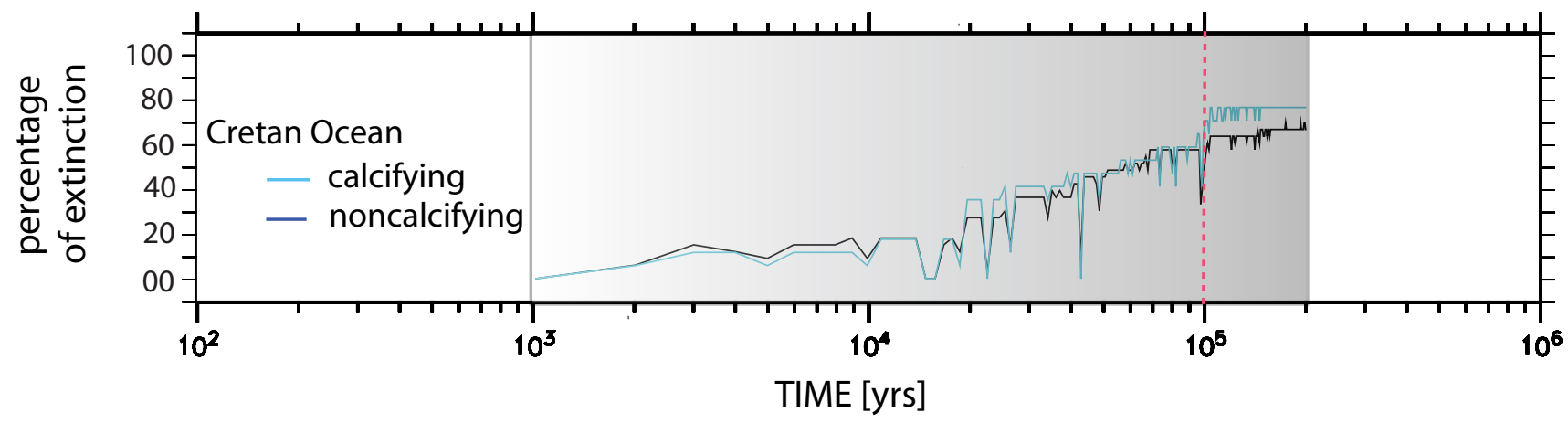



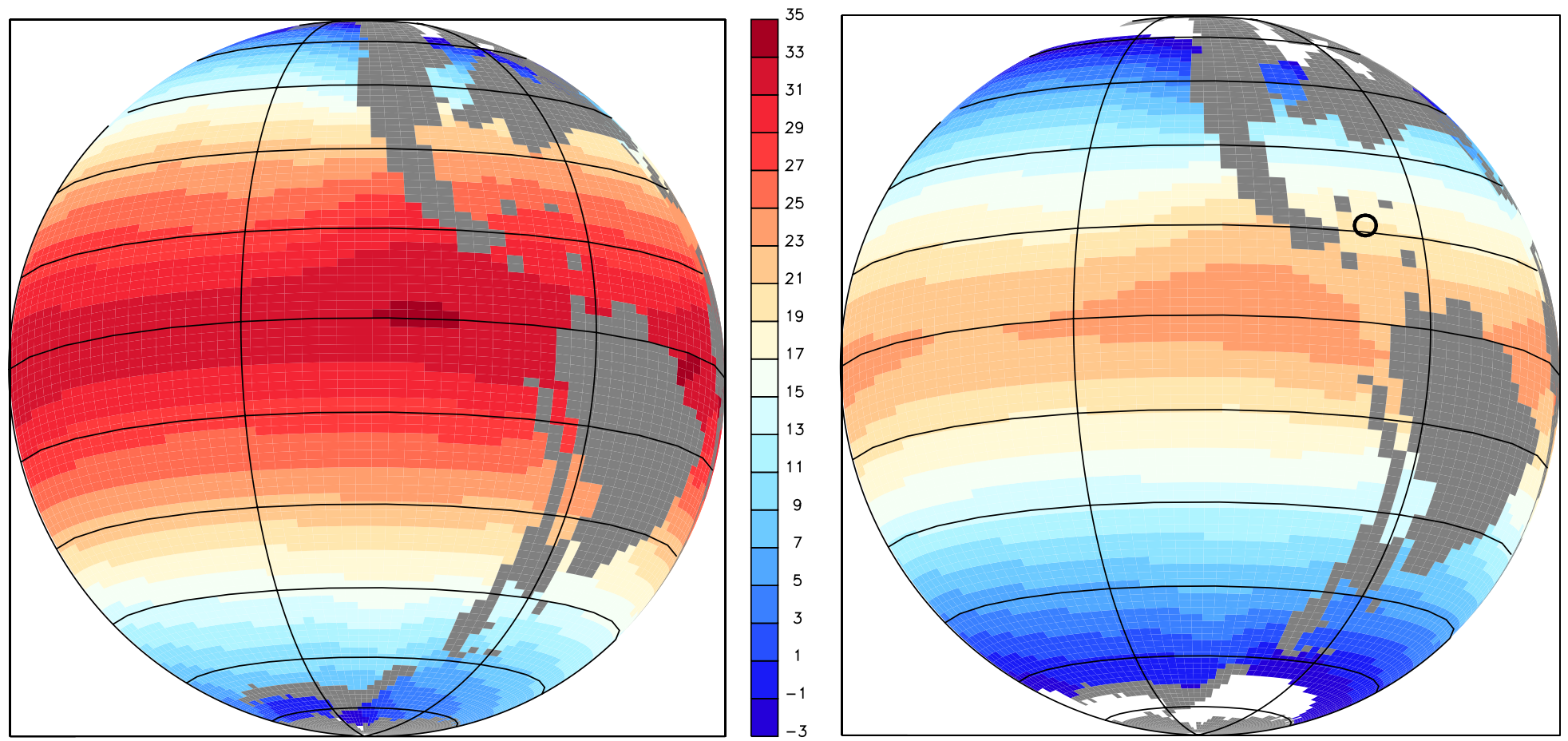

\section{Figure 10:}

SST patterns after 100 kyrs of emission (degassing fluxes available in electronic supplementary materials - fig.4 ). According to the AD-Cretan 1 experiment, the time coincidence between the traps of the impact of Chicxulub is fixed in half of the Deccan traps.

The left/right panel presents SST before/after the asteroid fell in Yucatan Peninsula (black circle). Corresponding oceanic disturbances are detailed in the fig. 9 